\title{
The role of linear wave refraction in the transient eddy-mean flow response to tropical Pacific SST anomalies.
}

\author{
N. Harnik $\dagger$, R. Seager $\dagger \dagger$, N. Naik $† \dagger$, M. Cane $\dagger \dagger$, and M. Ting $† \dagger$ \\ $\dagger$ Tel-Aviv University, Israel \\ $\dagger \dagger$ Lamont Doherty Earth Observatory, Columbia University \\ Contact: \\ Nili Harnik- harnik@tau.ac.il \\ Department of Geophysics \\ Tel Aviv University \\ Israel, 69978.
}

Submitted to the Quarterly Journal of the Royal Meteorological Society

April 28, 2010 


\section{Summary}

The midlatitude response to tropical Pacific SST anomalies involves changes in transient eddy propagation, but the processes leading to the transient eddy changes are still not clear. In a recent study, we used a series of controlled GCM experiments in which an imposed tropical Pacific SST anomaly is turned on abruptly and the response is analyzed in terms of its high and low frequency parts, to show that the ENSO induced changes in transient eddies arise from changes in wave refraction on the altered mean flow. In this work, we use a quasi-geostrophic linear model and a linear stationary wave model, to interpret the GCM experiments and obtain the sequence of events that lead from a tropical SST anomaly to the quasi-equilibrium change in the mean and transient atmospheric circulation. The initial direct response of the mean flow is confined to the tropical and subtropical Pacific, similar to what is obtained from a stationary wave model. This tropical-subtropical mean flow change initiates a transient eddy response, which induces a midlatitude mean flow anomaly. The wave-mean flow system evolves towards a state in which the eddy anomalies maintain the mean flow anomalies, allowing them to persist. It is further shown that while eddy momentum fluxes persistently accelerate and decelerate the subtropical and midlatitude mean flow, the eddy heat flux effect on the zonal mean flow is much more variable, and only marginally significant. The linear QG model calculations capture the evolution of eddy momentum flux anomalies equatorwards of $60^{\circ} \mathrm{N}$ quite well, suggesting linear wave refraction can explain the midlatitude ENSO anomalies. Other processes like stationary waves or changes in the nonlinear stage of eddy life cycles, however, are needed to explain the ENSO related anomalies at high latitudes, poleward of around $60^{\circ} \mathrm{N}$. 


\section{Introduction}

The El Niño - Southern Oscillation (ENSO) phenomenon is one of the leading climate signals, not only in the tropics, where it originates, but also in the extratropics, where its manifestation is indirect, and is generally considered in terms of a response to external forcing. The midlatitude response is characterized by a southward shift and zonal extension of the Pacific jet and storm track into the Southwestern US during El Niño (EN), and a northward deflection of the jet and storm track during La Niña (LN; Hoerling and Ting, 1994; Trenberth and Hurrell, 1994; Straus and Shukla, 1997; Compo and Sardeshmukh, 2004; Orlanski, 2005; Eichler and Higgins, 2006), with corresponding changes in precipitation systems (Schubert et al., 2004b,a; Seager et al., 2005b, 2008; Herweijer et al., 2006; Cook et al., 2007; Seager, 2007). ENSO also affects the Atlantic and Europe, but the response is not as robust as in the Pacific (e.g. Toniazzo and Scaife, 2006; Greatbatch et al., 2004; Bronnimann, 2007). The ENSO response also has a zonally symmetric component, with cooler and wetter midlatitudes, along with weaker and more equatorwards midlatitude jets during EN in both hemispheres (Seager et al., 2003, 2005a).

Earlier papers discussed the midlatitude response to ENSO in terms of linearly forced stationary extratropical wave trains (e.g. Horel and Wallace, 1891; Hoskins and Karoly, 1981), but the inherent role of transient eddies in maintaining, and maybe even creating parts of the extratropical response, has since been recognized and demonstrated in a variety of papers (e.g. Held et al., 1989; Hoerling and Ting, 1994). The emerging picture is one of a direct tropical-subtropical response to ENSO (described in terms of Kelvin and equatorial Rossby waves as in Gill, 1980), which jump-starts an eddy-mean flow positive feedback in mid-latitudes, in which the anomalies in transient eddies further strengthen the mean flow anomalies through the anomalies in eddy fluxes. Understanding how these eddy anomalies come about, and how they feedback onto the mean flow has been the focus of recent studies of the midlatitude response to ENSO. Straus and 
Shukla (1997), and Orlanski (2005) argue that increased baroclinicity in the Eastern Pacific, which is part of the direct response to tropical Pacific heating, is responsible for displacing the storm track southward and extending it eastward in that region. Orlanski $(2003,2005)$ also argues that central to the response is a change in the nonlinear decay stage of eddy life cycles, which is observed to occur (Shapiro et al., 2001; Martius et al., 2007; see also Gong et al, 2010) .

This paper focuses on a somewhat different mechanism, which involves an anomalous linear refraction of midlatitude transient waves, in response to the tropically driven large scale mean flow anomaly. This tropical modulation of midlatitude eddies (TMME) was examined in detail for the observed zonal mean response in Seager et al. (2003, hereafter S03). Recently, Seager et al. (2010, hereafter S10) performed a series of short (100 days) General Circulation Model (GCM) experiments, in which an ENSO anomaly is abruptly turned on, and time filtering is used to distinguish between the slower mean flow response, and the high frequency variations which constitute synoptic eddies. Analyzing the output of these runs, along with observations and a linear GCM, they explicitly showed that observed changes in the East Pacific storm track involve systematic changes in transient eddy propagation, consistent with changes in wave refraction. In this paper, we use the same set of GCM runs, along with a linear quasi-geostrophic (QG) model for the transient eddies, and a linear stationary wave model, to explicitly examine how the directly forced tropical ENSO response affects linear wave refraction over the Eastern Pacific, and how this TMME further acts to setup the observed midlatitude response there.

We first determine the different temporal stages in the circulation response to tropical Pacific SST anomalies in the GCM (Section 2.1) and show the limitations of the stationary waves in explaining this response without transient eddy effects (Section 2.2). We will then introduce the linear quasi-geostrophic model and the various diagnostics (Sections 3.1-3.2) which will be used to diagnose the role of transient eddies and wave-mean flow interaction in the GCM (Section 
3.3). In Section 3.4 we use the GCM runs to examine the equatorwards refraction during LN. We discuss the results and conclude in Section 4.

\section{The Circulation Response to tropical Pacific SST anomalies in GCMs and Stationary Wave Models}

Since SST anomalies evolve on a monthly to seasonal timescale, and the atmosphere is in quasiequilibrium with the underlying ocean, determining cause and effect is very difficult from observations. We thus turn to controlled model experiments.

\subsection{Controlled GCM experiments}

We use the GCM simulations presented in S10, in which we turn on an ENSO SST anomaly on December 1, run the model for 100 days, and examine the mean response averaged over a 100member ensemble. The model is the atmospheric NCAR Community Climate Model 3 (Kiehl et al., 1998). The different ensemble members are initialized from different December $1^{\text {st }}$ states taken from a long control integration, and for each of these initial conditions, we perform 100 day integrations using climatology, EN, and LN SSTs that differ only in the tropical Pacific SST. The imposed EN anomaly is the regression pattern of the December-February (1949-2008) Pacific SST anomaly on the NINO3.4 SST index (SST averaged over $5^{\circ} S-5^{\circ} \mathrm{N}, 170^{\circ} \mathrm{W}-130^{\circ} \mathrm{W}$ ), corresponding to a +1 standard deviation of the index, and applied between $20^{\circ} \mathrm{N}-20^{\circ} \mathrm{S}$. The LN anomaly is taken to be the opposite of that. These SST anomalies, which reach magnitudes of around $1^{o} \mathrm{~K}$ (for EN/LN, so $2^{o} K$ for their difference), give rise to the typical observed ENSO precipitation anomalies, similar to Seager et al. (2005a). The GCM response reproduces quite well many features of the observed response to ENSO (S10). We differentiate between the synoptic transient eddy variability, and a slower and larger scale variability, using a fourth-order Butterworth filter with a 10 day cut-off. The low-pass-filtered data plus the high-pass-filtered 
data are equal to the original field. We note that the different ensemble runs are created by using the December 1st initial conditions from different years of a long control integration. We use the November data preceding the initial conditions for each of the ensemble members, to calculate the filtered fields at initial times. We will show later on that the initial direct Gill-type response to ENSO is the low frequency response during the first week or so.

Figure 1 shows the EN minus LN $250 \mathrm{mb}$ zonal mean wind, the $250 \mathrm{mb}$ high-pass eddy momentum fluxes and $750 \mathrm{mb}$ eddy heat fluxes, from observations (National Centers for Environmental Prediction-National Center for Atmospheric Research Reanalysis) and from the GCM. The observations are determined by compositing the fields for DJF periods for which the three month Nino 3.4 index anomaly was greater than 1 standard deviation (EN) or smaller than -1 standard deviation (LN), while the GCM fields are the 50 - 100 day ensemble means. The eddy fluxes are the low-passed covariances of the high-pass fields. The levels are chosen to reflect the fact that the zonal mean jet and the eddy momentum fluxes peak in the upper troposphere while eddy heat fluxes are maximum in the lower troposphere. We shaded regions where the anomalies are significant at the $95 \%$ level, determined using a two-sided t-test, as follows. A given ENSO anomaly $A_{E N}-A_{L N}$ is significant where

$$
\frac{\left[A_{E N}\right]-\left[A_{L N}\right]}{\sqrt{s^{2}\left(A_{E N}\right) / N_{E N}+s^{2}\left(A_{L N}\right) / N_{L N}}}>t(p, d f)
$$

where $\left[A_{E N}\right]$ and $s\left(A_{E N}\right)$ represent the mean and sample standard deviation of quantity A during EN years, taken over the different ensemble members. Note that $s^{2}(A)=N r m s^{2}(A) /(N-1)$, where $\operatorname{rms}(A)$ is the root mean square of quantity $A . N_{E N}$ is the number of EN ensemble members and here $N_{E N}=N_{L N}=100$ for the GCM and $N_{E N}=10$ and $N_{L N}=12$ for the observations. The $t$-value, $t(p, d f)$, depends on the number of degrees of freedom, $d f,(d f \approx$ 200 for the GCM and $d f \approx 19$ for observations) and the significance level, $p$. For example, $t(95 \%, 200)=1.98$ and $t(95 \%, 19)=2.15$. 
We see that the GCM captures the main features of the anomalies, with the zonal mean wind anomaly being slightly weaker in the GCM but with very similar shape. The eddy flux anomaly patterns are also well captured, with the largest differences being off the east coast of Siberia (note that the GCM fields are smoother, probably due to the larger averaging sample). Since the zonal mean wind anomaly is strongest in the Eastern half of the Pacific, and we expect the synoptic eddies to be most sensitive to the anomaly there (rather than to the entire zonal mean flow), we perform our analysis for zonal mean flows which are longitudinally averaged over the Eastern half of the Pacific $\left(180^{\circ}-100^{\circ} \mathrm{W}\right)$.

Figure 2 shows latitude-time plots of the EN-LN low-passed zonal mean wind averaged over the Pacific region $\left(U_{P A C}\right)$ at $925 \mathrm{mb}$ (representing the surface) and $300 \mathrm{mb}$ (near the jet peak). Also shown is the vertically averaged $(0.5-18.6 \mathrm{~km})$ low pass filter of the high pass momentum flux $\left\langle\overline{u^{\prime} v^{\prime}}\right\rangle$, where an overline denotes a time averaging or low pass filtering, the angle brackets denote longitudinal averaging, the prime denotes high pass filtering, and $U$ denotes the low-pass zonal wind $\bar{u}$. We show the vertical average since the meridional convergence of this term (with a density weighting which hardly changes the shape of the quantity plotted) is a leading driving term of surface zonal wind anomalies (the barotropic component of the zonal wind). Light and dark shadings represent the $95 \%$ and $99 \%$ significance levels. We see a few stages in the evolution of these fields. Initially (up to about day 13), the wind anomaly at the surface is confined to the tropics (Figure 2a), and to the tropics and subtropics at upper levels (Figure 2b), and the eddy momentum flux anomalies are confined to the tropic before day 8 , when they start emerging in the subtropics (Figure 2c). The initial low-frequency response, which is confined to the tropical regions, before transient eddies emerge (days $1-7$ ), is the direct ENSO response. We note that in S03, we assumed somewhat arbitrarily, that the direct response to ENSO is the zonal mean response between $30^{\circ} S-30^{\circ} \mathrm{N}$, while the response at higher latitudes is eddy driven. Here we 
objectively disentangle the direct response from all the rest, at least initially.

At later times, the mean flow anomaly grows enough for the corresponding eddy momentum flux anomalies to become significant, and part of the low frequency large scale response to ENSO is driven by transient eddies. The eddy momentum flux anomaly emerges first in the subtropics, equatorwards of $40^{\circ} N$, and is mostly positive (days $8-20$, Figure 2c). Correspondingly, around day 13, a few days after the emergence of subtropical eddy momentum flux anomalies, a subtropical positive surface wind anomaly develops between $20^{\circ}-50^{\circ} \mathrm{N}$ (Figure 2a), while at upper levels the positive subtropical jet anomaly strengthens and expands poleward slightly (Figure 2b). We refer to this stage, as the initial eddy response stage. It is during this stage that eddy anomalies arise due to TMME, and cause the zonal mean wind anomalies to spread to mid latitudes.

The next stage starts between days 17 - 20, when significant negative midlatitude anomalies develop, both upper tropospheric zonal mean wind and transient eddy momentum fluxes, with a negative midlatitude surface wind anomaly evolving from around day 25. At this stage, eddy-mean flow interaction dominates the response, and we can no longer distinguish between the effect on eddy fluxes of the initial subtropical, and the subsequent midlatitude, mean flow anomalies. By this stage, the variability between individual ensemble members is large and time means are needed for robust statistics, but the slow evolution towards a statistical equilibrium is evident (though a longer integration might be needed to fully capture it).

\subsection{The purely stationary wave response to tropical SST anomalies}

In the previous section we argued that the low frequency response during the first week is the direct response to the ENSO forcing. In this part we verify that this response is indeed part of a tropically diabatically forced stationary wave train, which propagates poleward and eastward (Horel and Wallace, 1891; Hoskins and Karoly, 1981). We also examine how and when 
it is modified by transient eddies. To isolate this part of the response, we use the time-dependent linear stationary wave model of Ting and $\mathrm{Yu}$ (1998), in which a zonally varying basic state is specified, and a daily varying tropical heating from the GCM experiments is imposed, to obtain the low frequency (quasi-stationary) wave response. The calculation entails damping out the smaller scale transient eddies. The basic state is obtained by time averaging the ensemble mean low frequency flow of the GCM runs with climatological SST forcing. The time evolving diabatic forcing is taken from the $20^{\circ} \mathrm{N}-20^{\circ} \mathrm{S}$ daily mean diabatic terms of the EN and LN GCM runs. The linear stationary wave response to ENSO is obtained by imposing the EN minus LN GCM heating on the climatological basic state. This calculation is referred to as the pure stationary wave response. We also do a calculation where the effects of transient eddy vorticity fluxes are included by adding them as a forcing term to the vorticity equation. The time evolving eddy vorticity forcing is taken from the daily evolving low pass filtered correlation of high-passed vorticity and horizontal wind fields. We run the model for 100 days. For more details see Ting and $\mathrm{Yu}(1998)$.

Figure 3 shows the $300 \mathrm{mb}$ linear stationary wave (SW) $U$ anomaly (middle and right columns) alongside the ensemble mean GCM EN minus LN $U$ anomaly (left column), averaged over three time periods chosen to highlight a few points. The middle column is the pure $S W$ response - in which only tropical heating anomalies are imposed, while the right column shows the response to diabatic heating and transient eddy vorticity fluxes.

The days $1-7$ response (top row) is quite similar between the models, suggesting the initial GCM response is essentially the stationary wave response to the anomalous heating, as suggested above. At later stages, when the anomalies start spreading polewards, the stationary wave model and the GCM responses start to differ more, with the SW anomaly being stronger and more concentrated in the tropical region. Nonetheless, we see that the SW model with transient eddy 
forcing does a better job in spreading the anomalies polewards. For example, looking at the days $8-20$ response (middle row), we see that the negative Pacific zonal mean wind anomaly, which in the GCM starts poleward of $45^{\circ} N$ and extends over Alaska, is between $35^{\circ}-55^{\circ} N$ in the pure SW run, and between $45^{\circ}-65^{\circ} \mathrm{N}$ in the $\mathrm{SW}$ with transient eddy forcing.

This difference between the pure SW response and the transient eddy-influenced model runs persists as the anomalies equilibrate. Though both SW runs give a weak response over the extratropical Pacific and North America compared to the GCM, the response there is more realistic when transient eddy vorticity fluxes are included. This can be seen from the day 50 - 100 time mean response over the Pacific-American sector (Figure 3, bottom row) - the pure SW response is stronger in the tropical region and more compressed towards the equator, compared to the other two models. We next turn to understanding how the midlatitude response evolves.

\section{Diagnosing the wave mean flow interaction with a linear QG model and the GCM experiments}

The ability to separate out the direct ENSO response allows us to isolate the ENSO induced effect on midlatitude eddies quite cleanly, and to examine how this response further modifies the wave-mean flow dynamics, and in particular, how it feeds back onto the initial direct ENSO mean flow anomaly. For this, we use a spherical quasi-geostrophic (QG) linear steady state wave model which calculates the changes in wave structure due to changes in the mean flow (via a change in index of refraction). We note that the same model was used to analyze observations in S03, but there, the separation between the direct ENSO-induced mean flow anomaly and the secondary eddy-driven response was determined somewhat arbitrarily. The use of a zonal mean basic state, which obviously simplifies the analysis, implicitly assumes the effects of zonal transient 
eddy fluxes on the domain examined are negligible compared to the meridional fluxes (see Held et al., 1989, for some support of this).

\subsection{The linear QG model}

To determine the effect that a given mean flow anomaly will have on linear wave refraction, we use the linear QG model of S03. Briefly, for specified zonally-symmetric mean flow wind and temperature fields, the model solves the linear forced QG wave equation for geopotential streamfunction. The wave forcing is applied at the surface, and is assumed to be of a single zonal wavenumber. We specify the latitudinal structure of geopotential streamfunction amplitude and phase at the surface, and a constant eastward phase speed. Since we are simulating synoptic baroclinic waves, we also specify a constant exponential growth rate, which can also be thought of as a linear damping on potential vorticity (see Charney and Pedlosky, 1963). The wave solution also depends on the damping on temperature and momentum, which are assumed to be linear, with coefficients specified to be as small as possible for numerical stability. For more details, as well as the validity and limitations of the model for the present calculation, the reader is referred to S03 (see also Harnik and Lindzen, 2001).

We perform the linear QG model calculations as follows. The 100 runs of the GCM are averaged over each day, to obtain ensemble mean EN, LN and climatology runs. Zonal mean wind and temperature fields from each day are used as input for the linear QG model, and the corresponding solution for wave structure is calculated for each day, providing a 100 day record of the wave solution. The linear QG model domain extends higher than the GCM, to avoid downward reflection of waves from the top lid, and a higher resolution is used. Thus the zonal mean GCM fields are interpolated to the linear QG model grid, and are assumed constant with height beyond the top GCM level ${ }^{1}$.

\footnotetext{
${ }^{1}$ The linear QG model was written in log-pressure coordinates, hence we present results from it on log-pressure
} 
Once we obtain the wave geopotential streamfunction from the QG model, we calculate wave refraction and eddy fluxes. The effect on wave refraction in the meridional direction is expressed in terms of a meridional wavenumber squared $\left(l^{2}\right)$, which is diagnosed from the steady state wave geopotential streamfunction solution, as was done in S03 (see also Harnik and Lindzen, 2001). For a given zonal wavenumber and phase speed, $l^{2}$ indicates the mean flow ability to sustain the wave propagation, in particular, the tendency to refract waves. As with the index of refraction, waves tend to refract towards larger values, and away from lower values of $l^{2}$ (Karoly and Hoskins, 1982).

Anomalous changes in wave refraction necessarily imply changes in wave fluxes, which we can calculate from the linear QG model wave geopotential streamfunction field, as follows. We calculate the wave zonal and meridional wind anomalies ( $u^{\prime}$ and $v^{\prime}$ respectively) assuming geostrophy, and the wave temperature anomaly $\left(T^{\prime}\right)$ through the hydrostatic relation (our model is in logpressure coordinates). From these fields we calculate the eddy momentum and temperature fluxes (the covariances between the meridional wind and the zonal wind and temperature fields, respectively), denoted by $\left\langle\overline{u^{\prime} v^{\prime}}\right\rangle,\left\langle\overline{v^{\prime} T^{\prime}}\right\rangle$.

We repeat the calculation for EN and LN basic flows, and obtain the anomalies in eddy structure and fluxes by subtraction (e.g. the EN-LN anomalous momentum flux is then the difference in $\left\langle\overline{u^{\prime} v^{\prime}}\right\rangle$ between the EN and LN waves). The resulting anomalies can be thought of as the wave structure response to mean flow anomalies, arising from changes in wave refraction. We note that the model ignores changes in eddy phase speed, growth rate, or zonal wavenumber, all of which are held fixed. There is some support for this assumption in observational analyses (S10, Chen and Held, 2007) which suggest the most important changes during ENSO are indeed in wave refraction, and only to a lesser extent in the zonal wavenumber and phase speed (though height surfaces, and in $\mathrm{km}$. The GCM output, on the other hand is on pressure surfaces, hence we present results from it on pressure surfaces, and in $m b$. 
see Orlanski, 2005, who suggests the EN response is associated with smaller zonal wavenumbers developing in the eastern Pacific).

\subsection{The implied mean flow changes}

Once we obtain the wave momentum and heat flux fields, either from the GCM or from the linear QG model, we can calculate the eddy contributions to mean flow acceleration and warming. We use the zonal mean Transformed Eularian Mean (TEM) equations, in spherical coordinates, and under the QG assumptions. Though the TEM formulation considers the total effect of eddies via an Eliassen-Palm (EP) flux, we distinguish between the effects of eddy heat and momentum fluxes, as was done in S03.

Eddy effects on temperature enter through the TEM vertical velocity $\left\langle\bar{w}^{*}\right\rangle$, which under idealized conditions of steady, conservative, small amplitude waves, is equal to the mean Lagrangian vertical velocity (e.g. Andrews et al., 1987):

$$
\begin{gathered}
\frac{\partial\langle\bar{T}\rangle}{\partial t}+\left\langle\bar{w}^{*}\right\rangle S=Q \\
\left\langle\bar{w}^{*}\right\rangle=\langle\bar{w}\rangle+\frac{1}{a \cos \phi} \frac{\partial}{\partial \phi}\left(\frac{\left\langle\overline{v^{\prime} T^{\prime}}\right\rangle}{S} \cos \phi\right)
\end{gathered}
$$

$S \equiv \frac{\partial\langle\bar{T}\rangle}{\partial z}+\frac{g}{c_{p}} \frac{\langle\bar{T}\rangle}{T_{s}}$ is the static stability with $T_{s}$ a constant reference temperature, $Q$ is diabatic heating, $a$ the earth's radius, and $\phi$ is latitude.

Instantaneously, upward flow (positive $\left\langle\bar{w}^{*}\right\rangle$ ) will induce cooling, while in steady state, if $Q \propto-\langle\bar{T}\rangle$, as in simple Newtonian damping, an upward $\left\langle\bar{w}^{*}\right\rangle$ will balance a cold anomaly (negative $\langle\bar{T}\rangle$ ). $\left\langle\bar{w}^{*}\right\rangle$ includes a contribution from the eddy heat flux convergence, and the standard Eularian mean $\langle\bar{w}\rangle$, through which eddy momentum fluxes affect the mean temperature. To leading order, eddy momentum flux anomalies induce a mean meridional flow via the Coriolis force (to satisfy momentum balance, c.f. equation 3 of S03). The meridional flow, in turn, drives 
a vertical flow via continuity. The vertical velocity is thus

$$
\langle\bar{w}\rangle=\frac{1}{\rho} \int_{z}^{\infty} \frac{\rho}{a^{2} \cos \phi} \frac{\partial}{\partial \phi}\left(\frac{1}{\left.\cos \phi\left[f-\frac{1}{a \cos \phi} \frac{\partial}{\partial \phi}(\langle\bar{u}\rangle \cos \phi)\right)\right]} \frac{\partial}{\partial \phi}\left(\left\langle\overline{u^{\prime} v^{\prime}}\right\rangle \cos ^{2} \phi\right)\right) d z+\langle\bar{w}\rangle_{\text {other }}
$$

where the contribution of other effects besides eddy momentum fluxes to the vertical velocity are denoted by $\langle\bar{w}\rangle_{\text {other }}$. The eddy momentum flux contribution, expressed by the integral term, is the Haynes et al. (1991) "downward control" effect of wave driving.

S03 showed that the observed zonal mean midlatitude cold anomaly during EN is driven by anomalous eddy momentum flux-induced cooling, and damped by anomalous eddy heat flux warming. Repeating their analysis on the GCM, we find similar results, both for the full hemispheric zonal mean and for the Eastern half of the Pacific. Figure 4 shows the $50-100$ day averaged ensemble mean Eastern Pacific $\left(180-100^{\circ} \mathrm{W}\right.$ mean) temperature anomaly (plot a), alongside the corresponding contributions to the warming from the ensemble mean eddy momentum and heat fluxes (plots c and e respectively). Statistical significance calculations show all the anomalies contoured are significant at the $99 \%$ level. Looking at $30^{\circ}-50^{\circ} \mathrm{N}$, we see a negative temperature anomaly, cooling by eddy momentum fluxes, and a smaller warming by eddy heat fluxes. We note that a similar behavior, of momentum fluxes driving the observed geopotential height anomalies while heat fluxes oppose the observed associated temperature anomalies, was also found in the context of monthly PNA patterns Sheng et al. (1998).

S03 chose to emphasize the effects of the waves on the zonal mean temperature field (though they also examined the zonal momentum budget). Here we choose to emphasize the zonal mean wind field, since it accounts for the barotropic part of the dynamics which is important in the midlatitudes. For this we examine the zonal momentum equation: 
$\left.\frac{\partial\langle\bar{u}\rangle}{\partial t}-\left[f-\frac{1}{a \cos \phi} \frac{\partial}{\partial \phi}(\langle\bar{u}\rangle \cos \phi)\right)\right]\left\langle\bar{v}^{*}\right\rangle=\frac{1}{a \cos ^{2} \phi} \frac{\partial}{\partial \phi}\left(\left\langle\overline{u^{\prime} v^{\prime}}\right\rangle \cos ^{2} \phi\right)+\frac{1}{\rho} \frac{\partial}{\partial z}\left(\rho f \frac{\left\langle\overline{v^{\prime} T^{\prime}}\right\rangle}{S}\right) \equiv \frac{\nabla \cdot \vec{F}}{\rho \cos \phi}$

The second term on the LHS is the Coriolis effect of the residual mean meridional circulation $\left\langle\bar{v}^{*}\right\rangle \equiv\langle\bar{v}\rangle-\frac{1}{\rho} \frac{\partial}{\partial z}\left(\rho \frac{\left\langle\overline{v^{\prime} T^{\prime}}\right\rangle}{S}\right)$, which in steady state balances the eddy flux terms (so at least part of it arises in response to the eddy fluxes). The terms on the RHS are, respectively, the contribution of eddy momentum and heat fluxes, and they add up to the EP flux divergence $(\nabla \cdot \vec{F})$. Though we will refer to these terms here as contributions of eddy fluxes to the zonal wind acceleration, we should keep in mind that part of their effect will be directed into driving the mean meridional circulation, so that they represent an upper bound on the eddy contribution to $\frac{\partial\langle\bar{u}\rangle}{\partial t}$.

Figure 4 shows the 50 - 100 day averaged ensemble mean Eastern Pacific zonal mean wind anomaly (plot b), alongside the corresponding accelerations driven by the ensemble mean eddy momentum and heat fluxes (plots $\mathrm{d}$ and $\mathrm{f}$ respectively). We see a positive zonal mean wind anomaly between about $10^{\circ}-40^{\circ} \mathrm{N}$, and a negative anomaly poleward of that extending to around $70^{\circ} \mathrm{N}$. The eddy momentum flux acceleration is negative between $10^{\circ}-20^{\circ} \mathrm{N}$, positive between $20^{\circ}-40^{\circ} \mathrm{N}$, and negative between around $40^{\circ}-70^{\circ} \mathrm{N}$. The momentum flux acceleration tends to spread the subtropical positive jet anomaly polewards, consistent with its initial time evolution, and it tends to enhance the existing zonal mean wind anomaly between $30^{\circ}-70^{\circ} \mathrm{N}$. The contribution of heat fluxes, however, is more complex. The anomalous ENSO heat fluxes has a double-peaked vertical structure (not shown), similar to the climatological heat flux (e.g Peixoto and Oort, 1992). This yields the noisy heat flux-induced acceleration, because of the vertical derivative in Eq. 5 shown in Fig. 4 f.

The complex vertical structure of the heat flux-induced accelerations results in large temporal variations in its overall contribution. This is seen in Fig. 5 which shows latitude-time plots of the 
quantities shown in Fig 4b,d,f, averaged over 6.4-13.3km (400-150mb). Also shown (bottom plot) is the sum of the two eddy contributions. The light and dark shadings mark the $95 \%$ and $99 \%$ significance levels. We see that between $30^{\circ}-70^{\circ} \mathrm{N}$, at all times, the eddy momentum fluxes (Fig. 5b) act to enhance the zonal mean wind anomaly (Fig. 5a), with acceleration between $30^{\circ}-45^{\circ} N$ and deceleration poleward of that. The heat fluxes, on the other hand (Fig. 5c), are not as persistent, so that at times they enhance the midlatitude zonal mean wind anomalies, and at times they oppose it. Correspondingly, they are only marginally significant in midlatitudes. The more persistent momentum fluxes dominate on the whole, so that the total eddy-induced accelerations (Fig. 5d) look similar to the momentum flux contribution. Repeating the above calculations on a more westward domain $\left(140^{\circ} \mathrm{E}-120^{\circ} \mathrm{W}\right.$, not shown $)$ shows again a persistent reinforcing eddy-momentum flux contribution with a variable eddy heat flux contribution, but the relative role of eddy heat fluxes increases. This is expected since the western part of the storm track is where baroclinic generation is strongest. The statistical significance of the eddy accelerations, however, is lower than in the more eastern domain, with the momentum flux contribution being more statistically significant than that of the heat fluxes. It is also consistent with the observation that the zonal mean anomalies are strongest over the eastern Pacific.

\subsection{The role of linear wave refraction in initiating and maintaining the mid- latitude anomalies}

In this section we explicitly examine how anomalous wave refraction contributes to the mean flow evolution, by examining the wave geometry and by repeating the above analysis using the anomalous fluxes from the linear QG model.

\subsubsection{The initial direct ENSO response and its effect on transient eddies}

Figure 6a shows the EN-LN anomalous basic state $U_{P A C}$ and $\bar{q}_{y}$, averaged over days 1-7, taken from the GCM and imposed in the linear QG model. These anomalies represent the initial 
direct response to ENSO of the Pacific zonal mean flow. We see increased winds and $\bar{q}_{y}$ in the subtropical upper stratosphere.

Figure $6 \mathrm{~b}$ shows the critical surfaces, where the Pacific zonal mean flow equals the wave phase speed, calculated for EN (solid white contour) and LN (dashed white contour) using a a zonal wavenumber 6 and an angular phase speed corresponding to a period of 4.8 days $)^{2}$. We see that the increased winds during EN move the critical surface slightly equatorwards in the subtropical upper troposphere. Figure $6 \mathrm{~b}$ also shows the $1-7$ day mean QG model meridional wavenumber $l$ for climatology and the corresponding EN-LN anomaly. This quantity represents the effect of the index of refraction on meridional wave propagation, so that waves tend to propagate to higher values of $l^{2}$. Since waves can only propagate in regions of positive $l^{2}$, waves will be reflected from the line of $l^{2}=0$ (reflecting surface). $l^{2}$ also changes sign at the critical surface, where the zonal mean wind equals the zonal phase speed of the waves. At this surface, $l^{2}$ becomes infinite, and waves get absorbed in the linear limit or reflected in the nonlinear limit (e.g. Warn and Warn, 1978). From Fig $6 \mathrm{~b}$, the climatological $l$ is bounded by a reflecting surface $(l=0)$ on the poleward side, and a critical surface on its tropical side, with values increasing towards the subtropical critical surface. We see that the main effect of the EN mean flow anomalies is to shift the critical surface boundary equatorwards in the upper troposphere, resulting in a dipole structure, with a positive $l$ anomaly in the region into which the waveguide expanded, and a weaker, but more expansive, negative anomaly poleward of it. In much of the region, poleward of $40^{\circ} \mathrm{N}$, the waveguide is not much changed. The effect on the waves, however, is non local, and the equatorwards extension of the waveguide results in a small equatorwards shift, along with a slight weakening, of the wave pattern (not shown).

Figure 6c shows the EP flux anomaly from the QG model for days $1-7$. The anomaly is

\footnotetext{
${ }^{2}$ We also tried other wavenumbers and phase speeds and found similar results, as long as the wavenumbers and phase speeds considered were not too small (i.e. tending to stationary planetary waves).
} 
poleward and downward in most of the region poleward of around $35^{\circ}-40^{\circ} \mathrm{N}$ (where $l$ is small), and there is a strong equatorward anomaly near where the critical surface shifts equatorwards. The eddy heat flux anomaly in the linear QG model, which is proportional to the vertical component of the anomalous $\vec{F}$ of Equation 5 is negative polewards of about $40^{\circ} \mathrm{N}$, and positive equatorwards of it. Since the peak in climatological heat flux is around $45^{\circ} \mathrm{N}$, this represents a weakening along with an equatorwards shift. The anomalous momentum fluxes, which are proportional to minus the meridional component of $\vec{F}$, are equatorward between $35^{\circ}-55^{\circ} N$ and poleward in the upper troposphere around $20^{\circ} N$. Since the climatological momentum fluxes are poleward everywhere south of around $47^{\circ} \mathrm{N}$, and are strongest between $35^{\circ}-40^{\circ} \mathrm{N}$, this also represents a weakening and equatorwards shift. Repeating the linear QG model calculations for stationary planetary waves (not shown), using the full zonal mean flow (since planetary waves see the entire hemisphere and not only the Pacific), yields an overall strengthening of the waves and their upward flux to the stratosphere, consistent with previous studies (e.g. Fig. 5 of Garcia-Herrera et al., 2006). A more detailed examination shows that this has to do with choosing the full hemispheric zonal mean flow, since we also find an overall increase in wave fluxes for synoptic traveling waves, for the full hemispheric zonal mean flow ENSO anomaly.

Getting back to the Pacific region, the implied effect of the linear QG model momentum flux anomalies on the mean flow is shown in contours in Figure 6c. Besides the decelerationacceleration dipole straddling the critical surface region, we see a weak dipole emerging in mid latitudes, with deceleration at the poleward edge of the meridional waveguide, poleward of about $45^{\circ} \mathrm{N}$ and acceleration between $40^{\circ} \mathrm{N}$ and the critical line. This is consistent with the GCM simulations where we see a negative wind anomaly forming poleward of $45^{\circ} \mathrm{N}$ and a westerly anomaly spreading from the tropics into the mid-latitudes. 


\subsubsection{The initial eddy response stage and the TMME mechanism}

Figure 6d shows the $8-13$ day averaged EN-LN anomalous QG model basic state $U_{P A C}$ and corresponding $\bar{q}_{y}$. We choose to show this time period, when eddies start responding to the initial direct ENSO response, but have not yet modified the mean flow much (the TMME stage). We see the stronger positive subtropical wind anomaly and its extension poleward and downward to the surface, relative to days $1-7$, and a weak negative $U_{P A C}$ anomaly north of $45^{\circ} N$. The meridional wavenumber anomaly computed from the QG model (Figure 6e) also extends poleward at this stage. We note that since the GCM ensemble runs (from which the linear QG model basic state is taken) are based on a seasonally varying climatological flow, the climatological meridional waveguide structure changes in time. In particular we see that a midlatitude climatological minimum has developed around $40^{\circ} N$. During EN, this minimum deepens, resulting in the QG model in more equatorwards refraction south of it and more poleward refraction north of it (EP flux arrows, Figure 6f), similar to what was found in S03. This continued evolution of the momentum flux results in the strengthening within the QG model of the momentum flux induced mid-latitude acceleration-deceleration dipole pattern (Figure 6f, contours) implying a strengthening of the mid-latitude wind anomaly as actually happened in the GCM.

We have used the mean flow anomaly, beginning with the directly tropically forced part, as input for our linear QG model, and the resulting wave-flux anomaly, as calculated from our model, further induces patterns of acceleration and deceleration that match, in mid latitudes (poleward of the critical surface), quite well the tendencies in the Pacific zonal mean flow anomaly in the GCM. This suggests the linear eddy anomalies are able to maintain the mean flow anomalies. Next we examine whether this reinforcing eddy behavior holds beyond the initial eddy response stage, and into the subsequent eddy-mean flow interaction stage (day 20 and onwards). 


\subsubsection{The eddy-mean flow interaction stage}

Figure 7 shows a time-latitude plot of the vertically averaged $(6.2-13.1 \mathrm{~km})$ momentum and heat flux-induced accelerations, using the anomalous eddy momentum fluxes from the linear QG model. We also show for comparison (Fig. 7a) the vertically averaged GCM zonal mean wind anomalies, which are used as input for these model calculations. Comparing to Fig. 5, which shows the same quantities calculated from the anomalous GCM ensemble mean eddy fluxes, this indicates what part of the eddy-induced accelerations of the GCM can be accounted for by anomalous wave refraction.

Figure $7 \mathrm{~b}$ shows the eddy momentum flux acceleration has a relatively constant (in time) latitudinal tripole structure, which tends to spread the subtropical positive $U_{P A C}$ anomaly polewards, thus strengthening its poleward part, and to strengthen the negative midlatitude anomaly between $40^{\circ}-60^{\circ} N$. This is similar to the GCM eddy momentum flux accelerations (Fig. 5b), though the eddy-induced accelerations in the GCM are more noisy and extend further poleward (to about $\left.70^{\circ} \mathrm{N}\right)$.

The more poleward extension of deceleration in the GCM may be due to anomalous stationary wave fluxes which arise in response to the ENSO induced mean flow changes, and are absent from the linear QG model. In section 2.2, however, we saw that transient eddies, if anything, act to extend the pure stationary wave response poleward. However, it is possible that the planetary scale low frequency waves extend the eddy-driven response even further poleward, meaning their mutual interaction is important. It is also possible that transient eddy nonlinearities in the GCM act to extend the zonal mean wind anomalies poleward, in line with observations that link ENSO-induced changes in wave breaking to changes in the mean flow (Shapiro et al., 2001; Orlanski, 2003; Martius et al., 2007). Despite these differences, our results suggest that simple linear refraction can give rise to a positive wave-mean flow feedback in midlatitudes, which can 
explain a large part of the mean flow anomalies there, but that stationary wave anomalies and nonlinearities which are included in the GCM, but not in the QG model, are needed to fully account for the spreading of the positive $U_{P A C}$ anomalies to high latitudes during EN.

Figure 7c shows the corresponding plot for the heat flux induced acceleration (Equation 5, third term on RHS), again as calculated by the QG model. Unlike the GCM, where the effect of this process is very variable, the QG model heat flux-induced acceleration is quite constant in time, and is clearly negatively correlated with the observed $U_{P A C}$ anomaly, especially over the positive midlatitude $U_{P A C}$ anomaly $\left(40^{\circ}-60^{\circ} \mathrm{N}\right)$, but also over the subtropical positive anomaly between $\left(20^{\circ}-40^{\circ} \mathrm{N}\right)$.

Another feature of the QG model, which is in contrast to the GCM and to observations (S03), is that the heat fluxes dominate over momentum fluxes, essentially canceling their effect in midlatitudes, at least during the wave-mean flow interaction stage when anomalies are strong in midlatitudes ${ }^{3}$. This is an unrealistic feature of our model, which might be due to a few reasons. The ratio between momentum flux convergence and heat flux convergence, which determines the sign of the EP flux divergence (the total eddy effect, c.f. Equation 5), depends on damping, nonlinear terms, and the eddy growth rate. In our linear QG model, we specify damping and the eddy linear growth rate (in a way equivalent to adding a linear damping coefficient on potential vorticity), and nonlinear processes are neglected. Altering the values of damping in the linear QG model did not change the results qualitatively, which suggests nonlinearities are important in allowing the eddy momentum fluxes to dominate the response to mean wind anomalies once the anomalies expand to midlatitudes. This is consistent with the observation that eddy momentum fluxes dominate during the nonlinear equilibration stage of transient eddy life cycles (c.f. Edmon

\footnotetext{
${ }^{3}$ In contrast, momentum fluxes are dominant in both the observations and the linear QG model, when the anomalies are confined to the subtropics, as indicated by the positive total eddy acceleration between $30^{\circ}-50^{\circ} N$, before day 10, Fig. 7c, and the results presented in S03.
} 
et al., 1980). The linear QG model also does not account for diabatic processes associated with synoptic activity. Though the effects of diabatic heating, in particular due to moisture, on synoptic eddy fluxes is not well known, they are a source of difference between the GCM and our QG model.

\subsection{Enhanced wave refraction to the equator during La Niña}

An interesting phenomenon which S10 revealed is an enhancement of equatorwards refraction of wave packets from the central Pacific to the equatorial eastern Pacific during LN (e.g. Figures 5-7 of S10). This enhanced equatorward refraction during LN, occurs alongside a polewards shift of the main waveguide during LN. An examination of the time evolving wave geometry using the linear QG model explains this as part of the later stages of the response, as follows.

The EN-LN 300mb zonal mean wind anomaly is a tripole pattern, of equatorial deceleration, subtropical acceleration and midlatitude deceleration, which increases in magnitude with time (c.f. Figures 2b, 3b). This occurs alongside a steady equatorwards shift of the climatological jet (the jet peak moves from about $35^{\circ} N$ to $30^{\circ} N$ ), due to the imposed seasonal cycle. As a result of this southward shift, the climatological critical surface on the equatorwards side of the climatological jet, for the waves examined in the previous section, disappears towards midwinter, as is evident from the ensemble mean 35 - 100 day averaged climatological state (dashed line in Figure 8b). During EN, equatorial easterly anomalies allow a critical surface to form on the equatorwards side of the jet (Figure 8a). In contrast, during LN equatorial westerly anomalies make the critical surface disappear (Figure 8c). This suggests that during LN equatorward wave propagation is enabled more strongly, while during EN it is inhibited. That is, the stronger Walker Circulation during LN allows for equatorwards leaking of midlatitude upper level waves in the region of enhanced westerlies over the eastern tropical Pacific.

Note that at the same time, the midlatitude maximum in meridional wavenumber becomes 
more pronounced during LN. Based on the meridional wavenumber, we expect the equatorward waves during LN to be shallow, upper level wave packets, and the midlatitude waves to be deep. Figure 8 shows the GCM ensemble mean 35 - 100 day high passed mean meridional wind anomaly (represented by $\left\langle\overline{v^{\prime 2}}\right\rangle$ ), plotted on top of the meridional wavenumber, for EN, climatology and LN. We see indeed that during LN (Figure 8c) anomalies extend further equatorwards compared to EN and climatology, and that this extension is confined to the upper troposphere, following the meridional waveguide structure quite closely. At the same time, the anomaly strengthens in midlatitudes (compared to climatology and EN), consistent with the more pronounced midlatitude maximum in $l$. During EN (Figure 8a), on the other hand, the anomaly center shifts equatorwards (the peak in $\left\langle\overline{v^{\prime 2}}\right\rangle$ extends to $30^{\circ} \mathrm{N}$ at around $10 \mathrm{~km}$ only during EN), and this equatorward extension is deep, again consistent with the wave geometry. These results further strengthen our finding that the ENSO related changes in wave geometry can explain the observed anomalies in wave structure.

\section{Discussion and conclusions}

We have used a series of controlled GCM integrations, in which we abruptly turn on a Pacific SST anomaly consistent with El Niño or La Niña, to examine the time evolution of the atmospheric circulation response to ENSO. Using the ensemble-mean 100 day integrations for El Niño, La Niña and the climatological Pacific SST's, along with a linear QG model to diagnose the eddy structure and fluxes for a given daily mean flow, we are able to obtain an explicit picture of the evolution of wave and mean flow anomalies, as follows.

During El Niño, initially, the mean flow responds directly to the tropical El Niño heating with a strengthened Walker Circulation and upper level anticyclones straddling the heating anomaly (the direct ENSO response stage), with anomalous easterlies developing in the tropics 
and westerlies in the subtropics in the Eastern Pacific. This causes the critical surface on the equatorwards side of the jet to shift equatorwards in the upper troposphere subtropics. This objective determination of the initial direct response to ENSO is something which S03 were not able to do from their analyses. The linear wave response to this initial anomaly, as given by the QG model, is an equatorward shift and slight weakening of the waves, which induces a strong deceleration-acceleration dipole straddling the critical surface region in the subtropics, and a weak acceleration/deceleration south/north of about $40^{\circ} \mathrm{N}$. This pattern of eddy forcing is consistent with subsequent mean flow evolution in the GCM - the subtropical westerly anomaly spreads poleward, and an easterly zonal wind anomaly develops in the extratropics. The linear QG model then predicts that these new mean wind anomalies deepen the region in midlatitudes where there is a climatological meridional wavenumber minimum. The eddies will respond by refracting away from this deepened minimum, so that momentum fluxes strengthen equatorwards of around $40^{\circ} \mathrm{N}$, and weaken poleward of it. This has the effect, according to the linear QG model, of strengthening the mean wind acceleration in the subtropics and deceleration in midlatitudes. The waves and mean flow now enter into a positive feedback stage, with a quasi steady mean flow anomaly of subtropical westerlies and midlatitude easterlies emerging.

On top of this picture, there is the influence of stationary waves. The ENSO heating anomaly forces a stationary wave train out of the tropics and into midlatitudes. This wave train is concentrated at relatively low latitudes compared to the observed ENSO response. However, as transient eddies change the mean flow, the SW component also changes. Notably, it expands poleward so that the SW anomaly makes a non-negligible contribution at higher latitudes.

We also examine the different roles of eddy heat and momentum fluxes in establishing the mean flow anomalies. S03 found that during EN, anomalous eddy momentum fluxes force an anomalous ascent in midlatitudes, which cools the atmosphere there. Transient eddy heat fluxes, 
on the other hand, opposed this cooling, but their effect was smaller than that of momentum fluxes. We find a similar behavior in the GCM run when we examine the zonal mean temperature budget of the Pacific sector only. For the zonal momentum budget, we find again, that momentum fluxes quite persistently drive the anomaly, and in the linear QG model, the heat fluxes oppose it. However, in the GCM, the effect of heat fluxes is variable, so that they sometimes strengthen and sometimes oppose the midlatitude wind anomaly, and are only marginally significant. This variable contribution is due to the vertical double-peak structure of eddy heat fluxes. Overall, in the GCM, the momentum fluxes dominate the eddy driving of mean flow anomalies, while in the linear QG model, the heat fluxes dominate. This unrealistic behavior of the QG model is most likely due to the fact that the ratio of momentum to heat fluxes, which is manifest in the EP flux divergence, depends on eddy damping and nonlinearities. Eddy damping is parametrized crudely in the model (though varying the damping did not alter the results), and nonlinearities are completely absent. The QG model tells us how the wave geometry changes as a result of a given mean flow anomaly. The effect of wave geometry changes on the waves yields a realistic qualitative picture of how eddy momentum fluxes, and their corresponding induced acceleration and warming, are affected. The results suggest anomalous linear wave refraction is a central component of the midlatitude response to ENSO.

S10 showed that during El Niño, waves propagate along a more southern route, extending to the eastern Pacific and southern North American coast, while during La Niña, most of the waves turn along a more northward route across the Pacific, onto the Northern US and Canada. How do the present results fit with this picture? The climatological meridional waveguide has two branches, a subtropical one and a high-midlatitude one. During El Niño, the meridional wavenumber evolves so that its southern branch becomes more dominant. The minimum which separates the two waveguides deepens, so that more of the waves are refracted to the southern 
part. This sets off a positive wave-mean flow feedback which finally makes the southern part clearly dominant (e.g. Figure 8a). During La Niña, the opposite happens- waves extend more poleward because the minimum separating the two climatological waveguides is weakened, and the waves end up on a more northern route (e.g. Figure 8c). At the same time, the tropical wind anomalies allow leakage from the subtropical waveguide to the tropics during La Niña, resulting in the observed poleward and equatorwards split in wave propagation.

To conclude, the current work provides a plausible sequence of causality that links tropical sea surface temperature and heating anomalies to directly forced changes in the mean flow, a response of the transient eddies, and a subsequent impact on the mean flow. The transient eddy anomalies deduced from a linear QG model act to reinforce the mean flow anomalies in the subtropics and much of the midlatitudes, suggesting this simple mechanism can explain the robustness of ENSO-related North Pacific storm track variability and associated precipitation anomalies.

\section{Acknowledgments}

This work was supported by NSF grants ATM08-04107 and ATM05-43256 and NOAA grants NA06OAR4310151and NA03OAR4320179 and NA03OAR4320179. NH was supported by grant 1370/08 from the Israeli Science Foundation. 


\section{References}

Andrews, D. G., J. Holton, and C. B. Leovy, 1987: Middle Atmosphere Dynamics, Academic Press, pp 489.

Bronnimann, S., 2007: Impact of El Niño-Southern Oscillation on European climate., Rev. Geophys., 45, RG3003.

Charney, J. G. and J. Pedlosky, 1963: On the trapping of unstable planetary waves in the atmosphere, J. Geophys. Res., 68, 6441-6442.

Chen, G. and I. M. Held, 2007: Phase speed spectra and the recent poleward shift of Southern Hemisphere surface westerlies, Geophys. Res. Lett., 34, L21805, doi:10.1029/2007GL031200.

Compo, G. P. and P. Sardeshmukh, 2004: Storm track predictability on seasonal and decadal timescales., J. Clim., 17, 3701-3720.

Cook, E., R. Seager, M. A. Cane, and D. Stahle, 2007: North American drought: Reconstruction, causes and consequences., Earth Sci. Rev., 81, 93-134.

Edmon, H. J., B. J. Hoskins, and M. E. McIntyre, 1980: Eliassen-Palm cross-sections for the troposphere., J. Atmos. Sci., 37, 2600-2616.

Eichler, T. and W. Higgins, 2006: Climatology and ENSO-related variability of North American extratropical cyclone activity., J. Clim., 19, 2076-2093.

Garcia-Herrera, R., N. Calvo, R. R. Garcia, and M. A. Giorgetta3, 2006: Propagation of ENSO temperature signals into the middle atmosphere: A comparison of two general circulation models and ERA-40 reanalysis data, J. Geophys. Res., 111, D06101, doi:10.1029/2005JD006061.

Gill, A., 1980: Some simple solutions for heat-induced tropical circulations., Q. J. R. Meteorol. Soc., 106, 447-462.

Gong, T., S. B. Feldstein, and D. Luoa, 2010: The impact of ENSO on wave breaking and Southern Annular Mode events, J. Atmos. Sci., in press. 
Greatbatch, R. J., J. Lu, and K. A. Peterson, 2004: Nonstationary impact of ENSO on EuroAtlantic winter climate., Geophys. Res. Lett., 31, L02208.

Harnik, N. and R. S. Lindzen, 2001: The effect of reflecting surfaces on the vertical structure and variability of stratospheric planetary waves, J. Atmos. Sci., 58, 2872-2894.

Haynes, P. H., C. J. Marks, M. E. McIntyre, T. G. Shepherd, and K. P. Shine, 1991: On the "downward control" of extratropical diabatic circulation by eddy-induced mean zonal forces, J. Atmos. Sci., 48, 651-678.

Held, I. M., S. W. Lyons, and S. Nigam, 1989: Transients and the extratropical response to El-Nino, J. Atmos. Sci., 46, 163-174.

Herweijer, C., R. Seager, and E. R. Cook, 2006: North American droughts of the mid to late nineteenth century: A history, simulation and implications for Medieval drought, The Holocene, 16, 159-171.

Hoerling, M. P. and M. Ting, 1994: Organization of extratropical transients during El Niño., J. Clim., 7, 745-766.

Horel, J. D. and J. Wallace, 1891: Planetary-scale atmospheric phenomena associated with the Southern Oscillation., Mon. Wea. Rev., 109, 813-829.

Hoskins, B. J. and D. Karoly, 1981: The steady linear response of a spherical atmosphere to thermal and orographic forcing, J. Atmos. Sci., 38, 1179-1196.

Karoly, D. J. and B. J. Hoskins, 1982: Three dimensional propagation of planetary-waves, J. Meteor. Soc. Japan, 60, 109-123.

Kiehl, J. T., J. Hack, G. Bonan, B. Boville, D. Williamson, and P. Rasch, 1998: The National Center for Atmospheric Research Community Climate Model: CCM3, J. Clim., 11, 11311149.

Martius, O., C. Schwierz, and H. Davies, 2007: Breaking waves at the tropopause in the win- 
tertime Northern Hemisphere: Climatological analyses of the orientation and the theoretical lc1/2 classification., J. Atmos. Sci., 64, 2576-2592.

Orlanski, I., 2003: Bifurcation in eddy life cycles: Implications for storm track variability., J. Atmos. Sci., 60, 993-1023.

Orlanski, I., 2005: A new look at the Pacific storm track variability: Sensitivity to tropical SSTs and to upstream seeding., J. Atmos. Sci., 62, 1367-1390.

Peixoto, J. P. and A. H. Oort, 1992: Physics of Climate, American Institute of Physics, pp. 520.

Schubert, S. D., M. J. Suarez, P. Pegion, R. Koster, and J. Bacmeister, 2004a: Causes of long term drought in the United States Great Plains., J. Clim., 17, 485-503.

Schubert, S. D., M. J. Suarez, P. Pegion, R. Koster, and J. Bacmeister, 2004b: On the cause of the 1930s Dust Bowl., Science, 303, 1855-1859.

Seager, R., 2007: The turn of the century drought across North America: global context, dynamics and past analogues, J. Clim., 20, 5527-5552.

Seager, R., N. Harnik, Y. Kushnir, W. Robinson, and J. Miller, 2003: Mechanisms of hemispherically symmetric climate variability., J. Clim., 16, 2960-2978.

Seager, R., N. Harnik, W. Robinson, Y. Kushnir, M. Ting, H. Huang, and J. Velez, 2005a: Mechanisms of ENSO-forcing of hemispherically symmetric precipitation variability., $Q . J . R$. Meteorol. Soc., 131, 1501-1527.

Seager, R., Y. Kushnir, C. Herweijer, N. Naik, and J. Miller, 2005b: Modeling of tropical forcing of persistent droughts and pluvials over western North America: 1856-2000, J. Clim., 18, 4065-4088.

Seager, R., Y. Kushnir, M. Ting, M. Cane, N. Naik, and J. Miller, 2008: Would advance knowledge of 1930s SSTs have allowed prediction of the Dust Bowl drought?, J. Clim., 21, $3261-3281$. 
Seager, R., N. Naik, M. Ting, M. A. Cane, N. Harnik, and Y. Kushnir, 2010: Adjustment of the atmospheric circulation to tropical Pacific SST anomalies: Variability of transient eddy propagation in the Pacific-North America sector, Q. J. R. Meteorol. Soc., 136.

Shapiro, M. A., H. Wernli, N. A. Bond, and R. Langland, 2001: The influence of the 1997-99 El Nino-Southern Oscillation on extratropical life cylces over the eastern north pacific., $Q . J . R$. Meteorol. Soc., 127, 331-342.

Sheng, J., J. Derome, and M. Klasa, 1998: The role of transient disturbances in the dynamics of the Pacific North american pattern, J. Clim., 11.

Straus, D. M. and J. Shukla, 1997: Variations of midlatitude transient dynamics associated with ENSO, J. Atmos. Sci., 54, 777-790.

Ting, M. and L. Yu, 1998: Steady response to tropical heating in wavy linear and nonlinear baroclinic models, J. Atmos. Sci., 55, 3565-3582.

Toniazzo, T. and A. A. Scaife, 2006: The influence of ENSO on winter North Atlantic climate., Geophys. Res. Lett., 33, L24704.

Trenberth, K. E. and J. W. Hurrell, 1994: Decadal atmosphere-ocean variations in the Pacific, Clim. Dyn., 9, 303-319.

Warn, T. and H. Warn, 1978: The evolution of a nonlinear critical level, Stud. Appl. Math, 59, 37-71. 

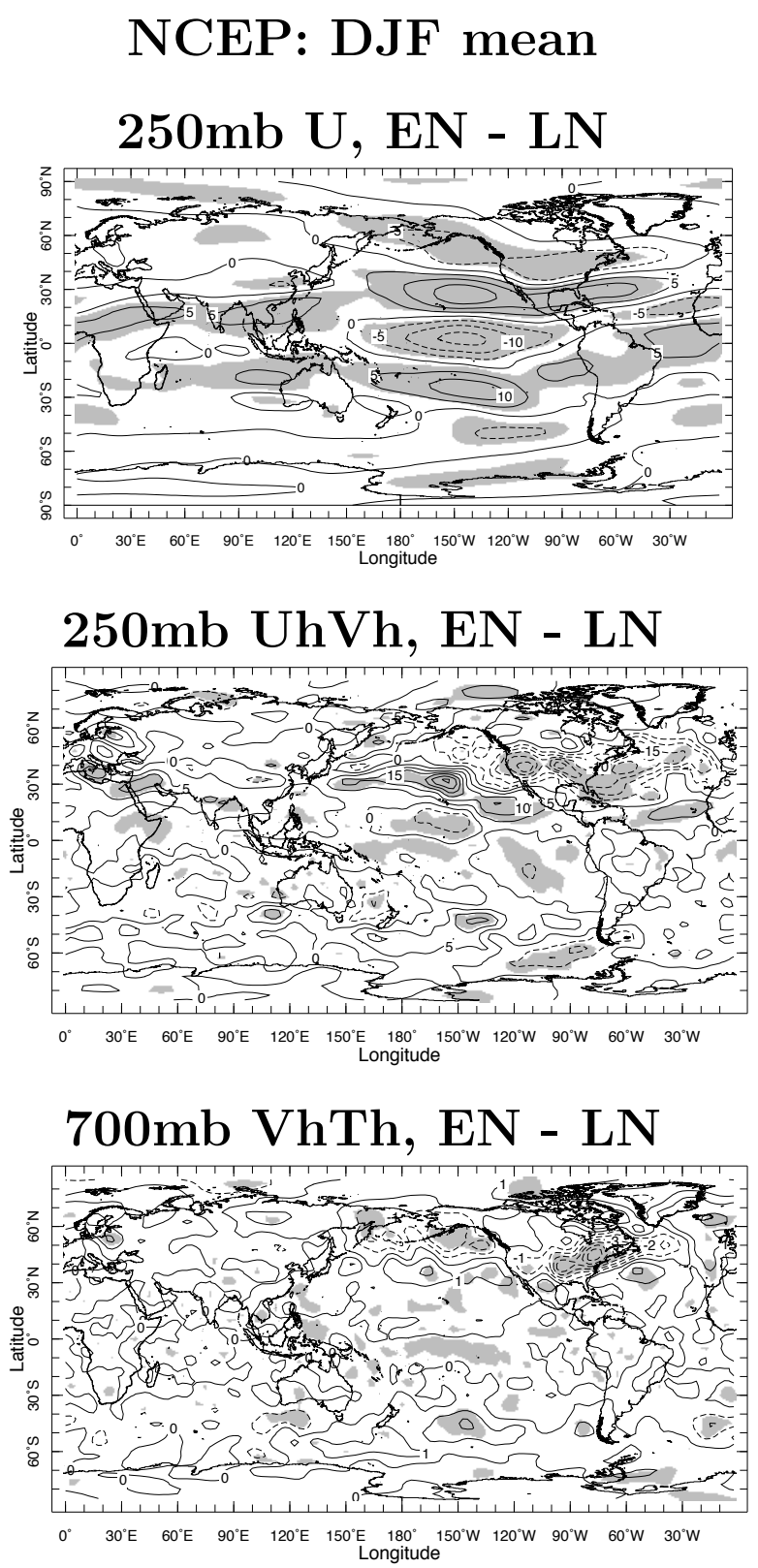

GCM: 50-100 day mean
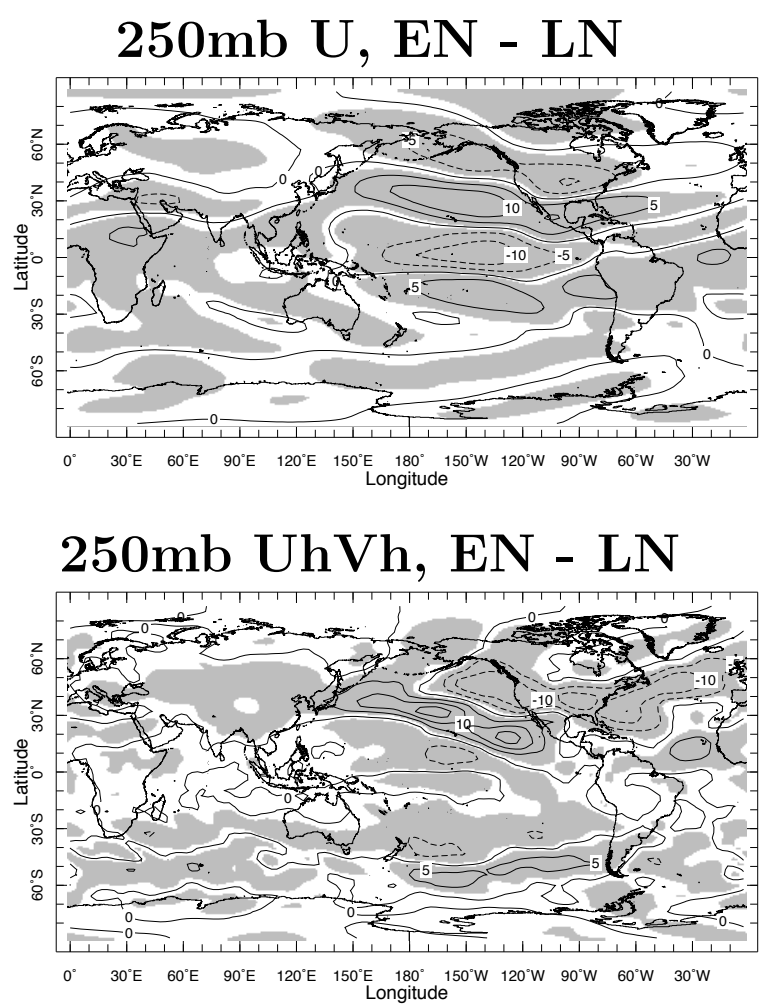

700mb VhTh, EN - LN

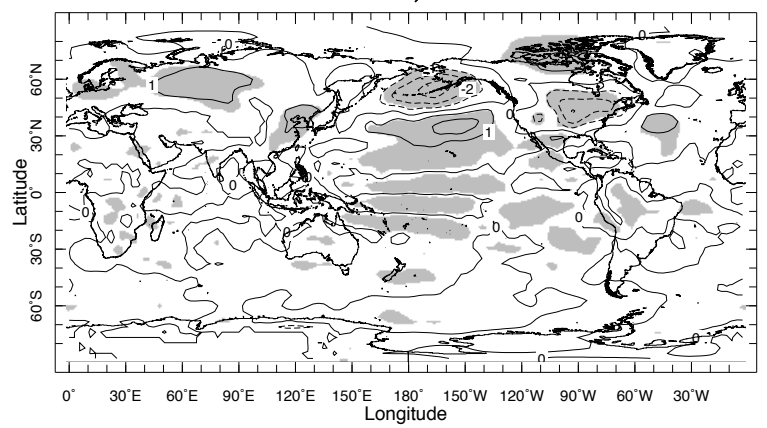

Figure 1: NCEP reanalysis DJF mean (left column) and the GCM ensemble mean 50 - 100 day averaged (right column) fields: Top: $250 \mathrm{mb}$ zonal mean wind $(\mathrm{m} / \mathrm{sec}$ ). Middle: $250 \mathrm{mb}$ high-pass eddy momentum flux $\left(\mathrm{m}^{2} / \mathrm{sec}^{2}\right)$. Bottom: $750 \mathrm{mb}$ eddy heat flux $\left({ }^{\circ} \mathrm{Km} / \mathrm{sec}\right)$ The eddy fluxes are the low-passed covariances of the high-pass fields. Shading indicates the $95 \%$ significance in the observations (left plots), and 99\% significance for the GCM fields (right plots), using a two-sided t-test. Negative values are dashed. Contour interval is \pm 5 for the zonal mean wind and eddy momentum fluxes, and \pm 1 for the eddy heat fluxes. 
a) $\mathrm{U}$ at $925 \mathrm{mb}, \mathrm{EN}-\mathrm{LN}$

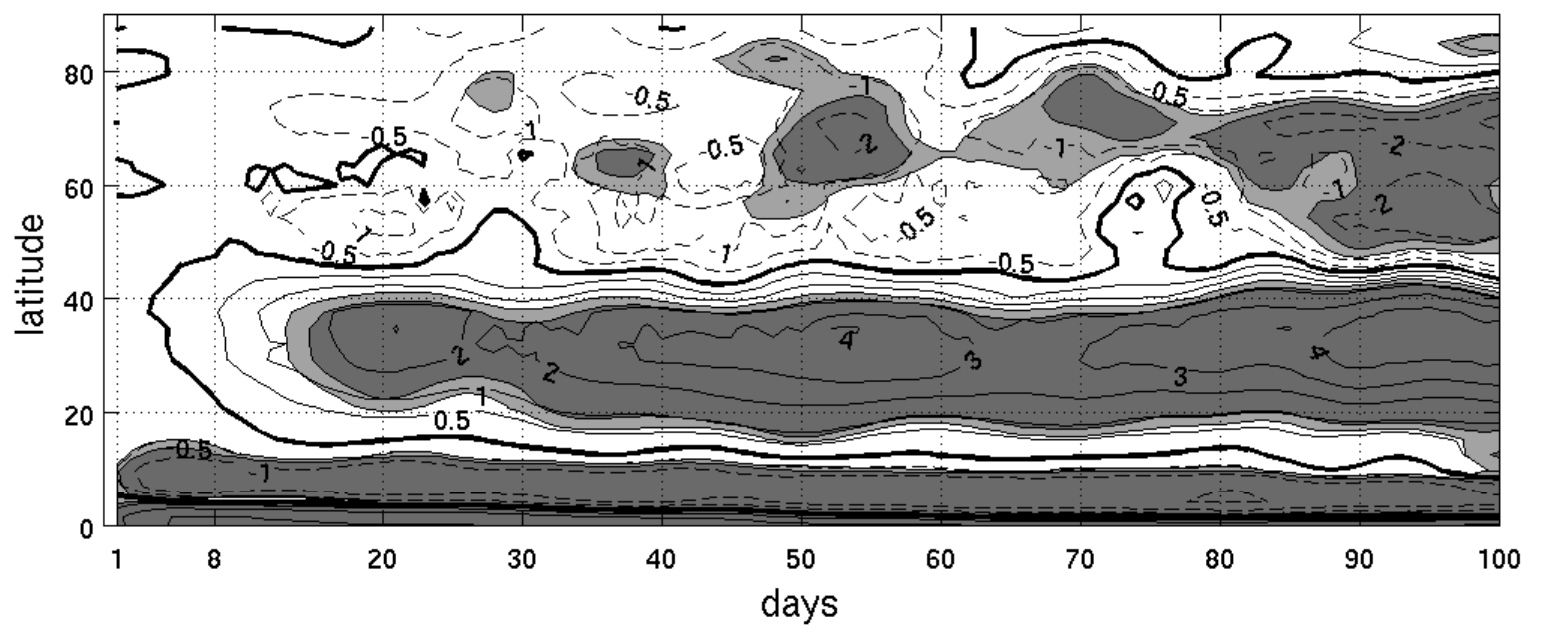

b) $\quad U$ at $300 \mathrm{mb}$, EN-LN

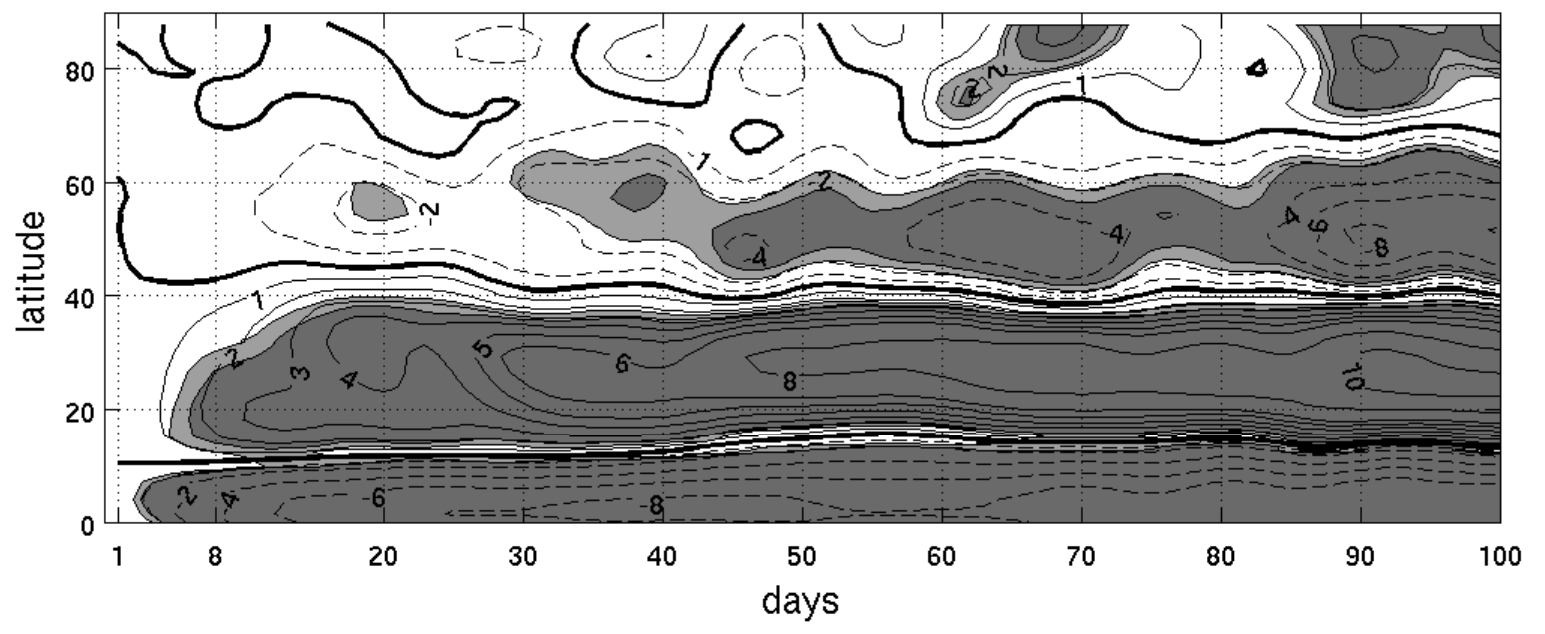

c) $u^{\prime} v^{\prime}$, averaged over $925-150 \mathrm{mb}$ EN-LN

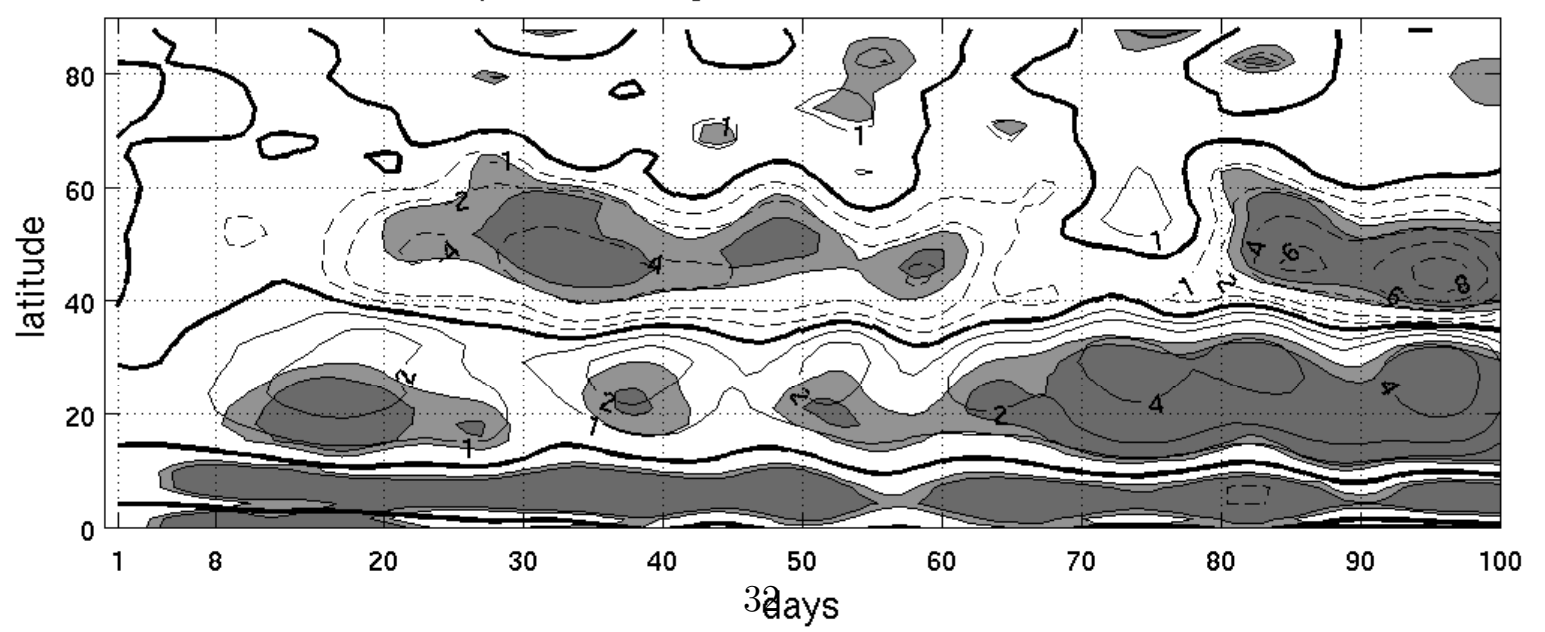

Figure 2: Time-latitude plots of the EN-LN ensemble mean GCM fields: a) $U_{P A C}$ at $925 \mathrm{mb}$, b) $U_{P A C}$ at $300 \mathrm{mb}$. c) Ensemble mean vertically averaged $(925-150 \mathrm{mb})<\overline{u^{\prime} v^{\prime}}>$, averaged over the Pacific sector. The meridional convergence of this quantity (density weighted) drives the surface winds. Units are $\mathrm{m} / \mathrm{sec}$ for the top two plots and $\mathrm{m}^{2} / \mathrm{sec}^{2}$ for the bottom plot. the $95 \%$ and $99 \%$ significance levels are marked by the light and dark shadings. The time axis tick-marks at initial times are placed to mark the different evolution stages. 


\section{GCM}

\section{Days 1-7}

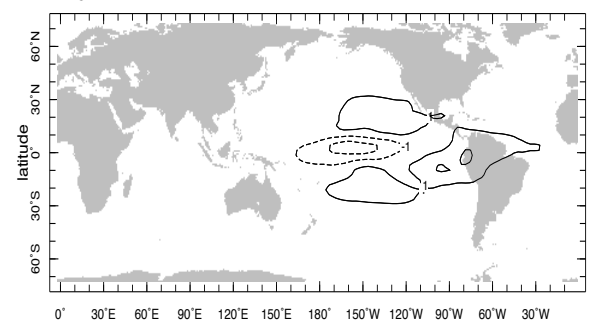

\section{Days 8-20}

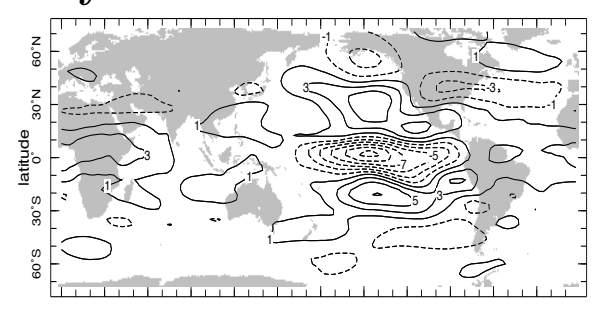

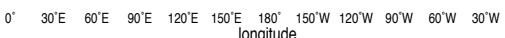

\section{Days 50-100}

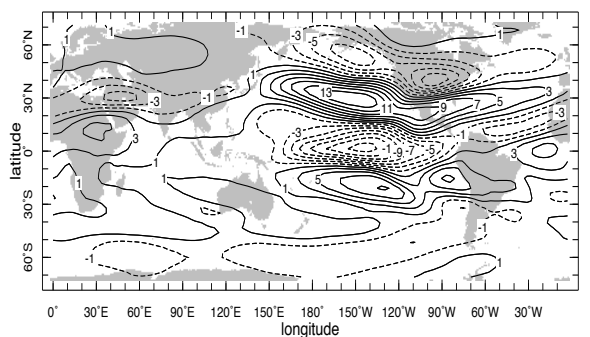

\section{Linear Model}

with

tropical heating
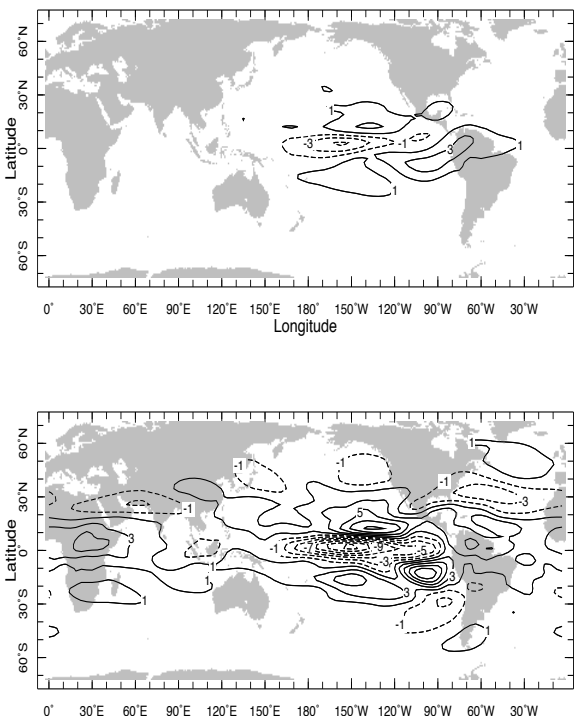

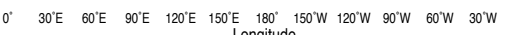

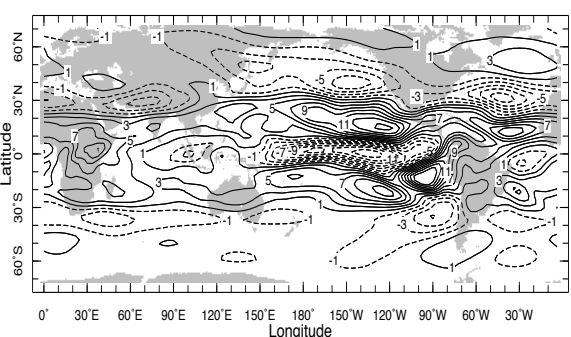

Linear Model

with

tropical heating

and vorticity TE forcing

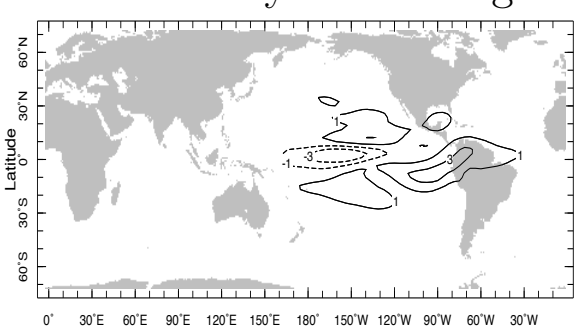

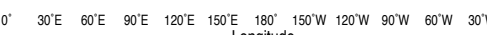

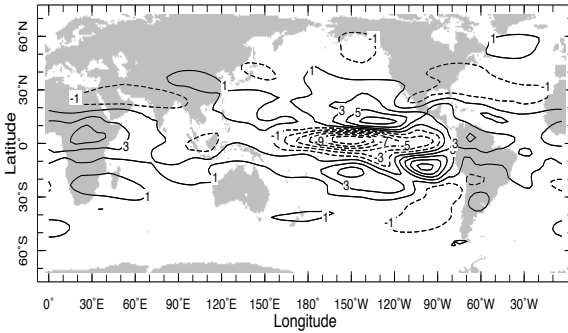

O. $30^{\circ} \mathrm{E} \quad 60^{\circ} \mathrm{E} \quad 90^{\circ} \mathrm{E} \quad 120^{\circ} \mathrm{E} \quad 150^{\circ} \mathrm{E} \quad 180^{\circ} \quad 150^{\circ} \mathrm{W} \quad 120^{\circ} \mathrm{W} \quad 90^{\circ} \mathrm{W} \quad 60^{\circ} \mathrm{W} \quad 30^{\circ} \mathrm{W}$

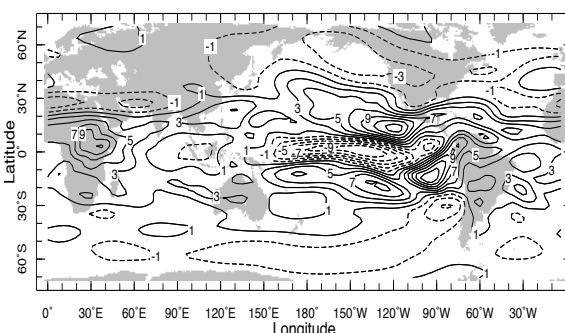

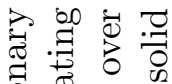

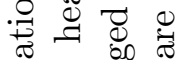

荡.

O

$\exists: \frac{\pi}{7}$

สี

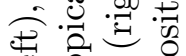

$\stackrel{\theta}{\rightarrow}$ y 2

ت답

定

施

पष

ช

武

है: च्०

5 व

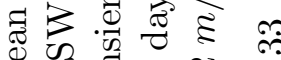

घ $\widetilde{N}$

() ฮี

의 연

政

$\exists \circ 0 . \exists$

$\sum$ 중

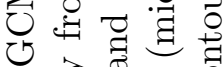

ไ สี

है है 1

表

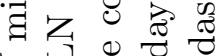

z의

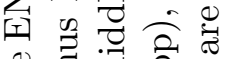

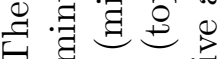

品实人

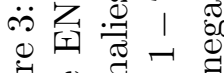

范 뭉

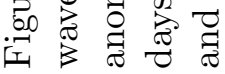


a) EN-LN T

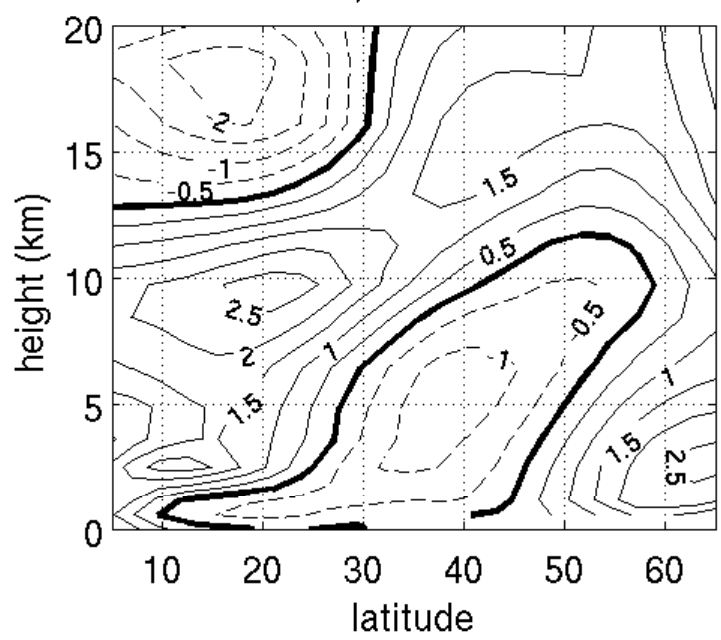

c) EN-LN u' $v^{\prime}$ induce $T_{t}$

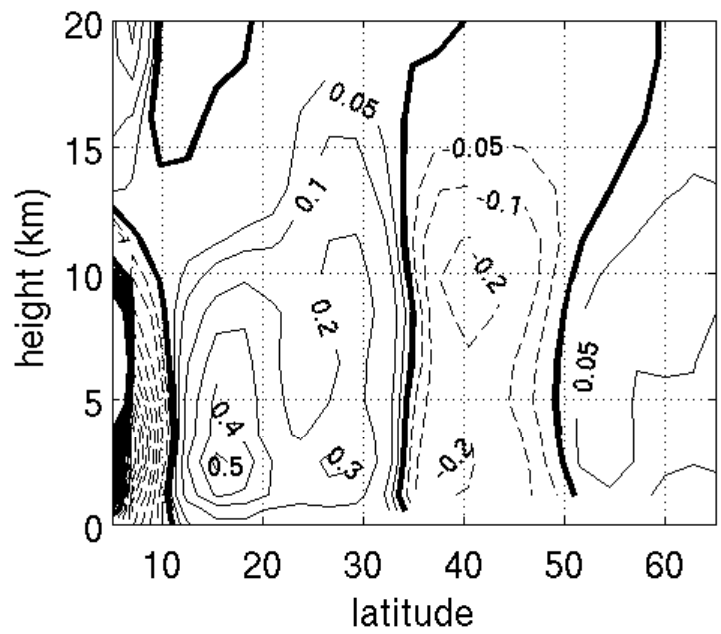

e) EN-LN $v^{\prime} T^{\prime}$ induce $T_{t}$

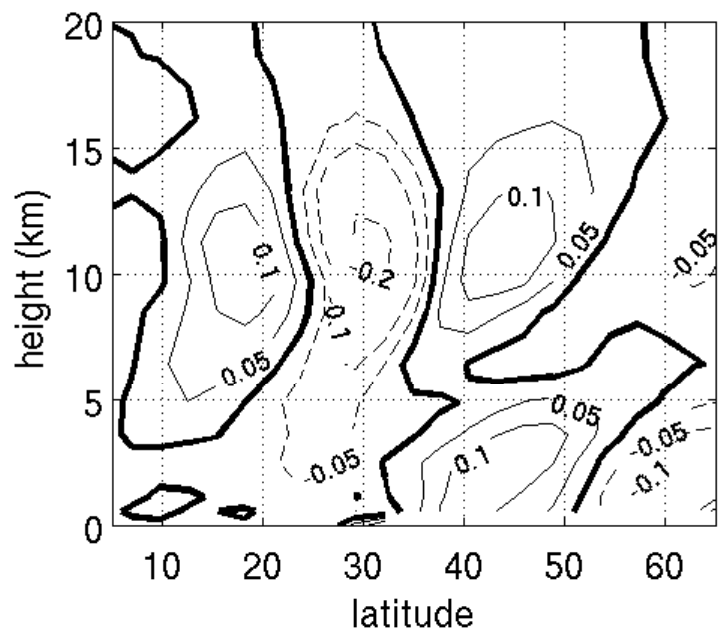

b) EN-LN U

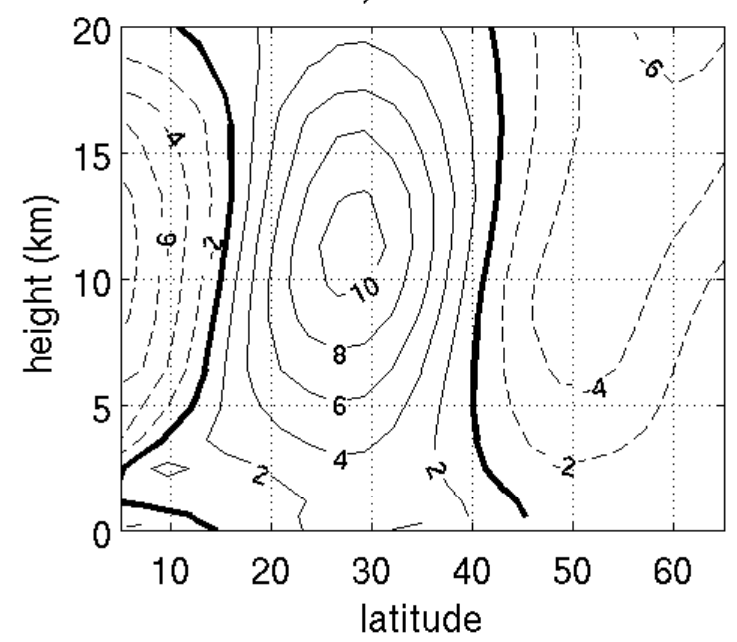

d) EN-LN $u^{\prime} v^{\prime}$ induce $U_{t}$

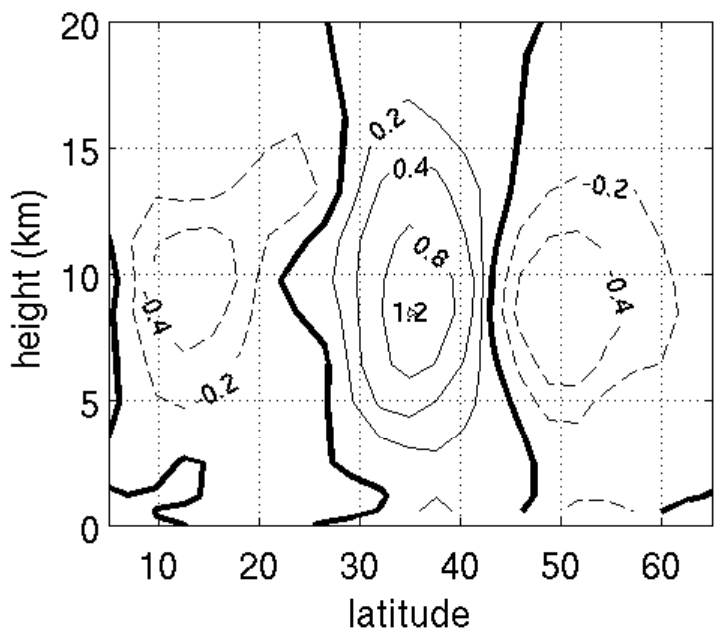

f) EN-LN $v^{\prime} T^{\prime}$ induce $U_{t}$

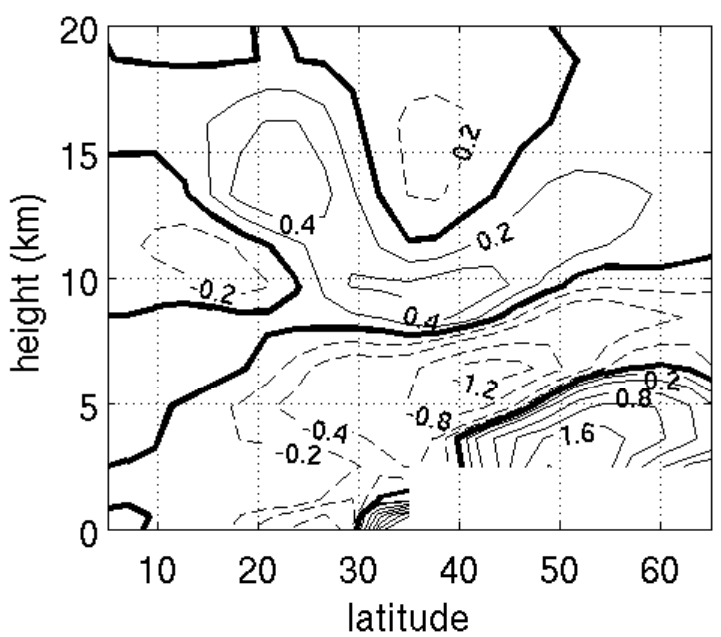

Figure 4: a) Latitude-height plots of the $50-100$ day $180^{\circ}-100^{\circ} \mathrm{W}$ averaged EN-LN ensemble mean GCM $T_{P A C}(\mathrm{~m} / \mathrm{sec})$ (a) and $U_{P A C}\left({ }^{\circ} \mathrm{K}\right)(\mathrm{b})$, and the corresponding eddy momentum and heat flux induced warming $\left({ }^{\circ} \mathrm{K} /\right.$ day $)(\mathrm{c}, \mathrm{e})$ and accelerations $(\mathrm{m} / \mathrm{sec} /$ day $)(\mathrm{d}, \mathrm{f})$ respectively. Negative values are dashed and zero line is thick. All anomalies contoured are significant at the $99 \%$ level. 
a) EN-LN 6-13km mean U

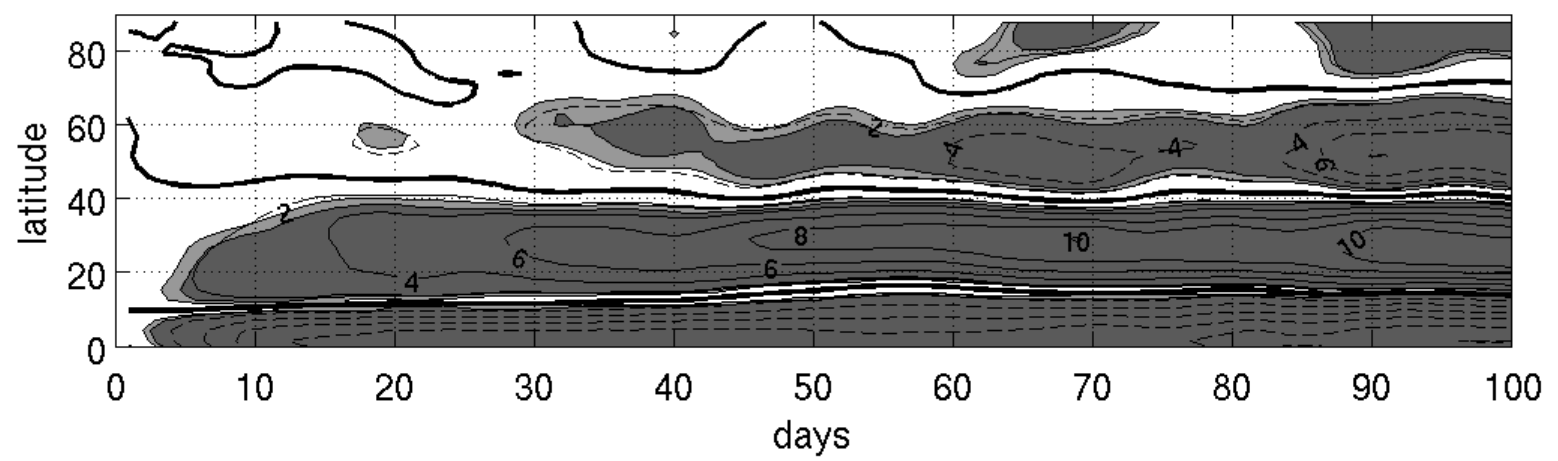

b) EN-LN 6-13km mean u'v' acceleration

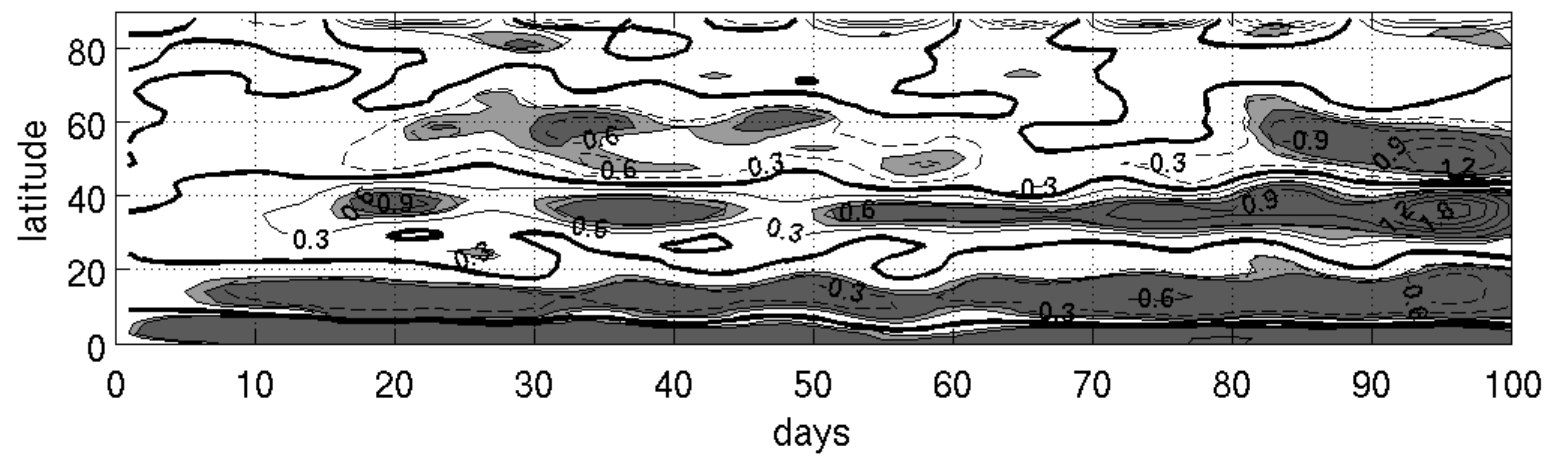

c) EN-LN 6-13km mean $v^{\prime} T^{\prime}$ acceleration

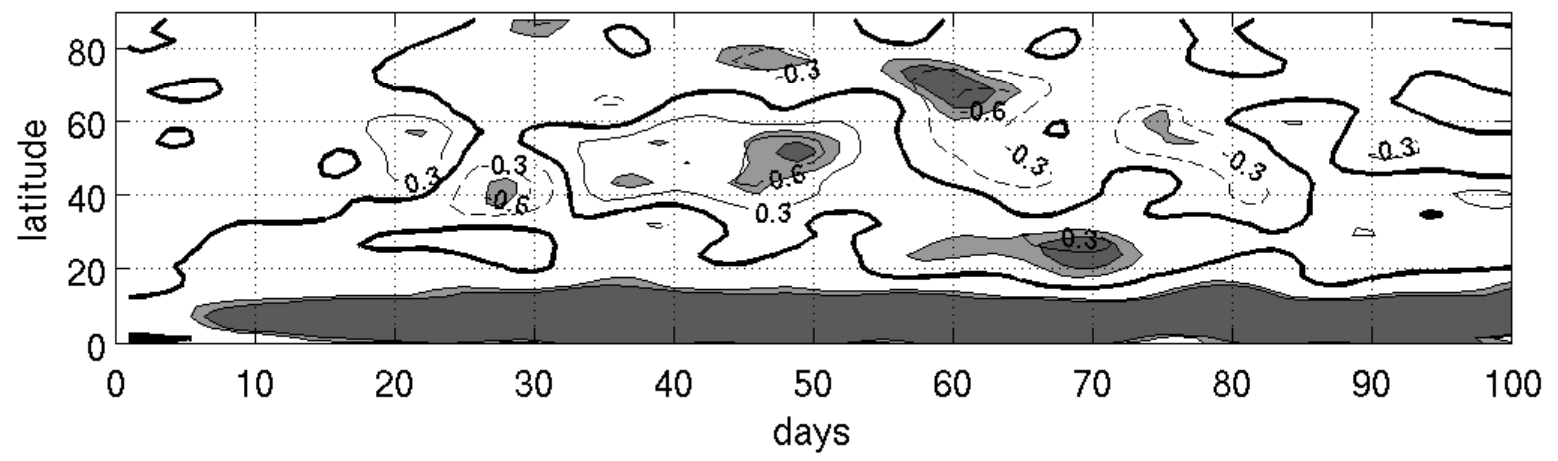

d) EN-LN 6-13km mean sum of $u^{\prime} v^{\prime}$ and $v^{\prime} T^{\prime}$ acceleration

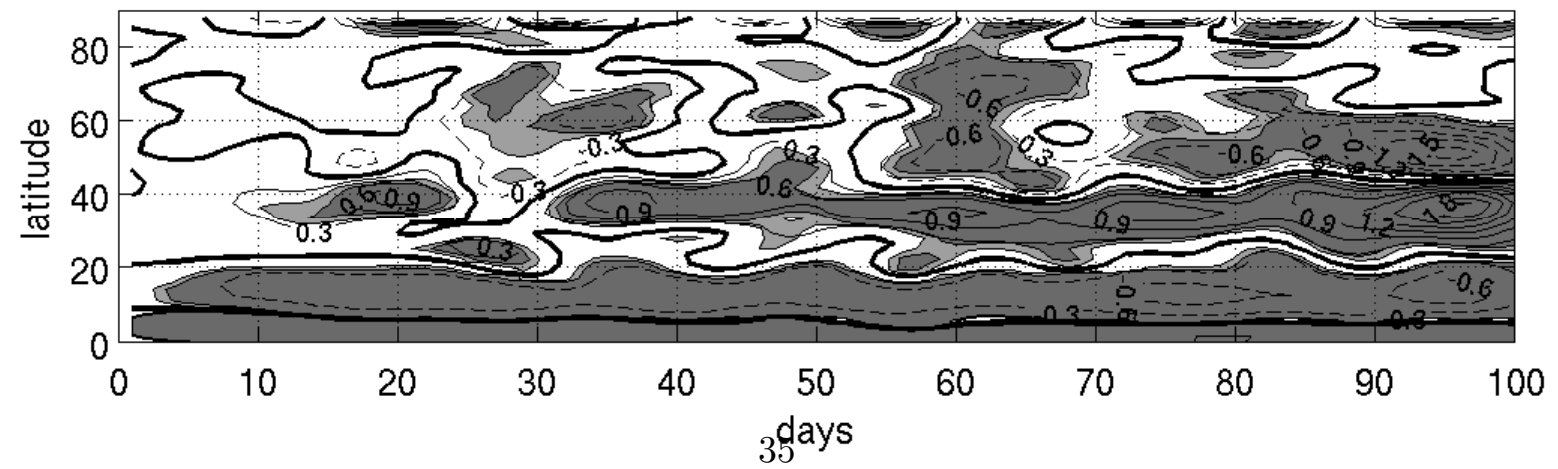

Figure 5: Time-latitude plots of the vertically-averaged $(6.4-13.3 \mathrm{~km}), 180^{\circ}-100^{\circ} \mathrm{W}$ mean, ENLN ensemble mean GCM fields: a) $U_{P A C}(\mathrm{~m} / \mathrm{sec})$. b) The eddy momentum flux contribution to acceleration $(\mathrm{m} / \mathrm{sec} / \mathrm{day})$. c) The eddy heat flux contribution to acceleration. d) The sum of the heat and momentum flux accelerations. In all plots, negative values are dashed and the zero contour is thick. The contour intervals are $2 \mathrm{~m} / \mathrm{sec}$ in (a) and $0.3 \mathrm{~m} / \mathrm{sec} / \mathrm{day}$ in (b)-(d). Regions of $95 \%$ and $99 \%$ significance are shaded in light a dark gray, respectively. 

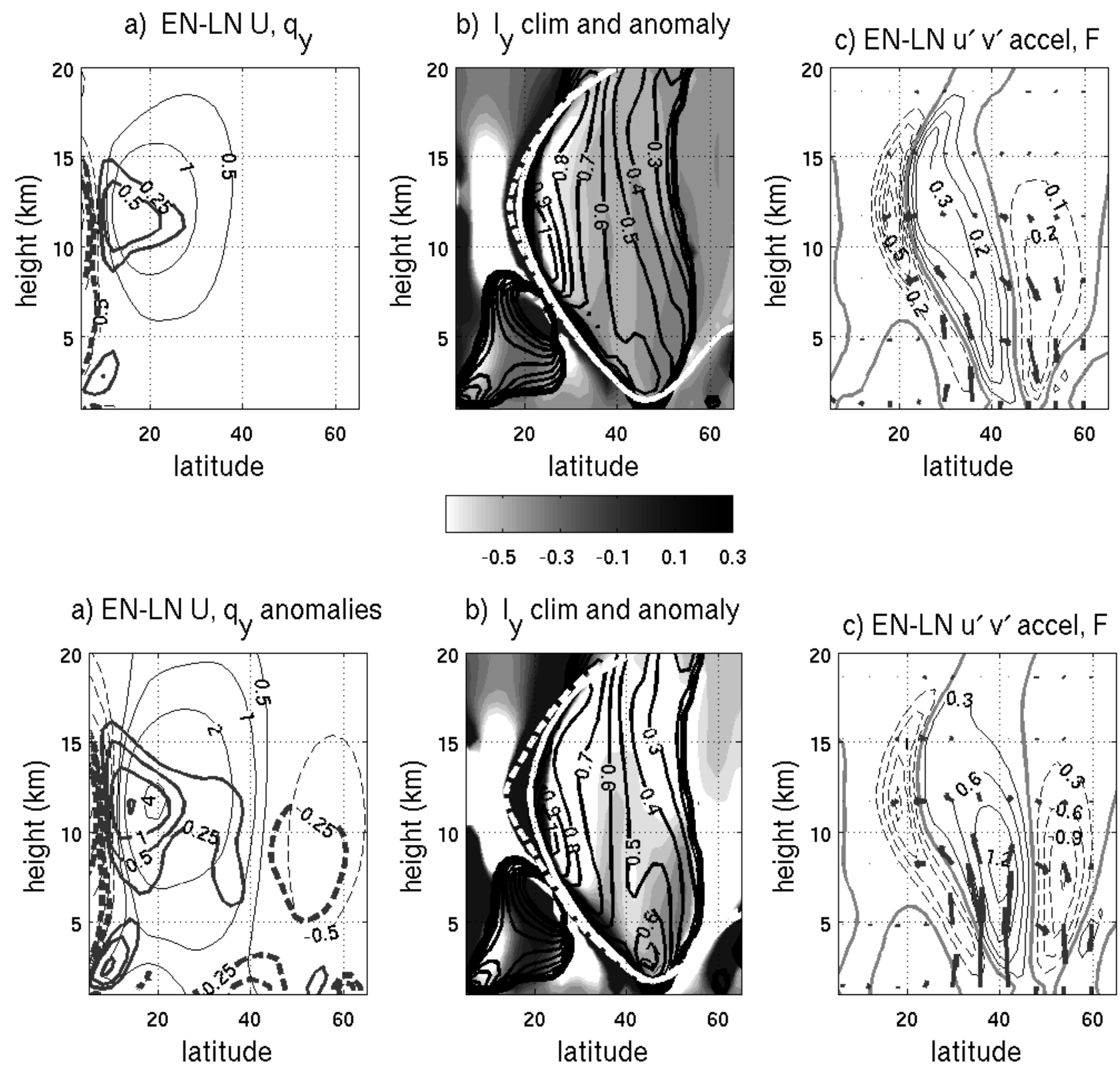

c) EN-LN u' $v^{\prime}$ accel, F
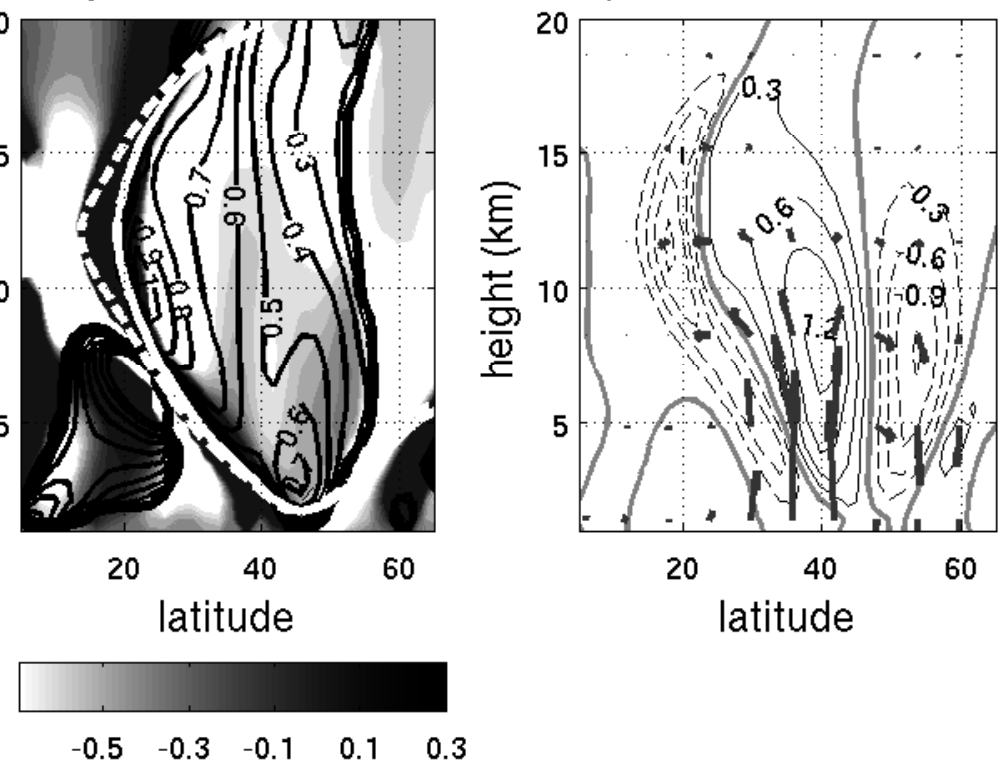

Figure 6: Latitude-height plots of the linear QG model fields (run with the Pacific mean flow). $1-7$ day means: a) EN-LN U $(\mathrm{m} / \mathrm{sec}$, thin black contours $)$ and $q_{y}\left(\times 10^{11} \mathrm{sec}^{-1} \mathrm{~m}^{-1}\right.$, thick dark gray contours). b) The meridional wavenumber $\left(\mathrm{rad}^{-1}\right)$ climatology (black contours, only real values are shown), and the EN-LN anomaly (shading, bright to dark), and the EN (solid white) and LN (dashed white) critical surface $3\left(U_{P A C}=c_{p h}\right)$. c) The momentum flux induced acceleration (second term on RHS of Equation 5, contours) and the EN-LN EP flux anomaly (arrows). Dashed lines in (a) and (c) are negative. The zero line in (c) is thick gray. (d)-(f) like (a)-(c) only for the $8-20$ day means. Note that wave amplitudes, and correspondingly the magnitudes of wave fluxes, are arbitrary in the liner QG model. 
a) EN-LN 6-13km mean U

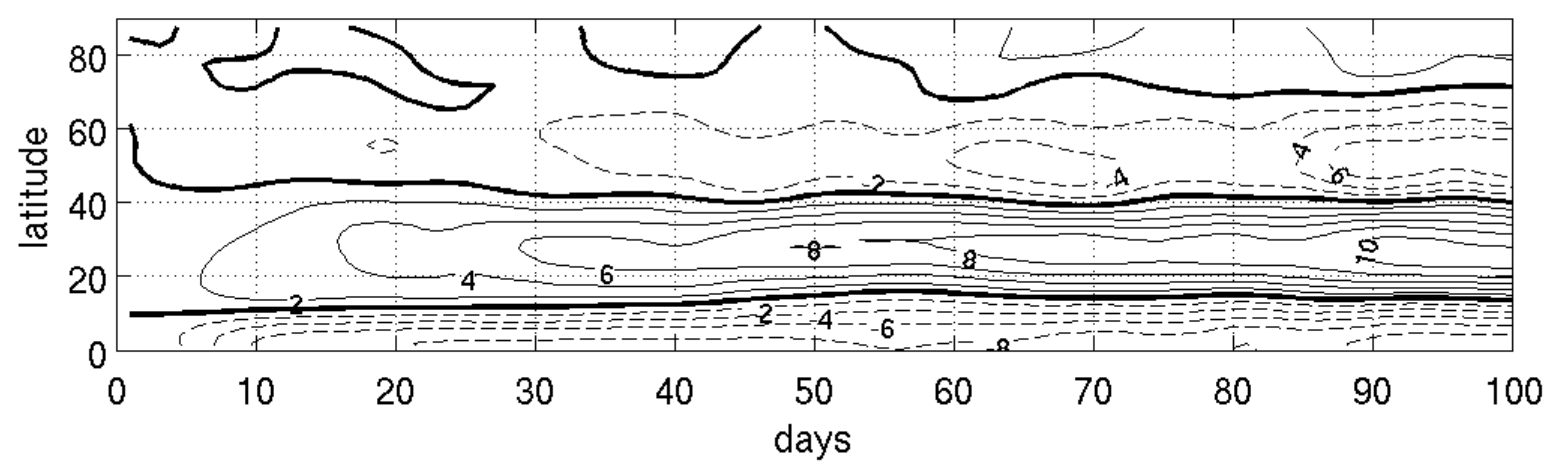

b) EN-LN 6-13km mean QG u'v' acceleration

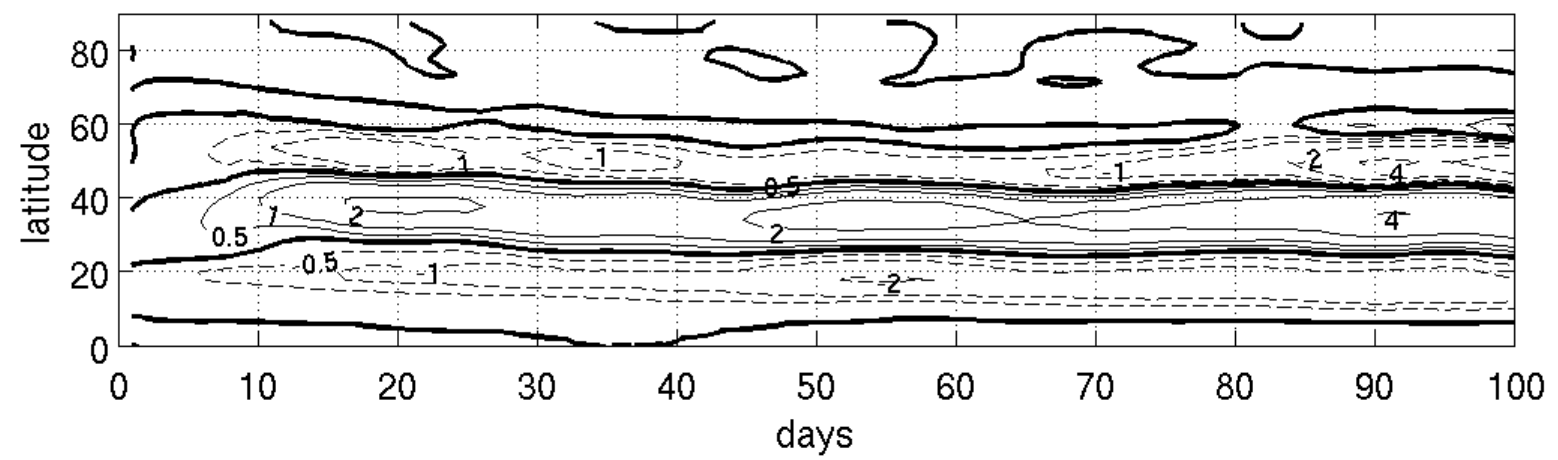

c) EN-LN 6-13km mean QG v'T' acceleration

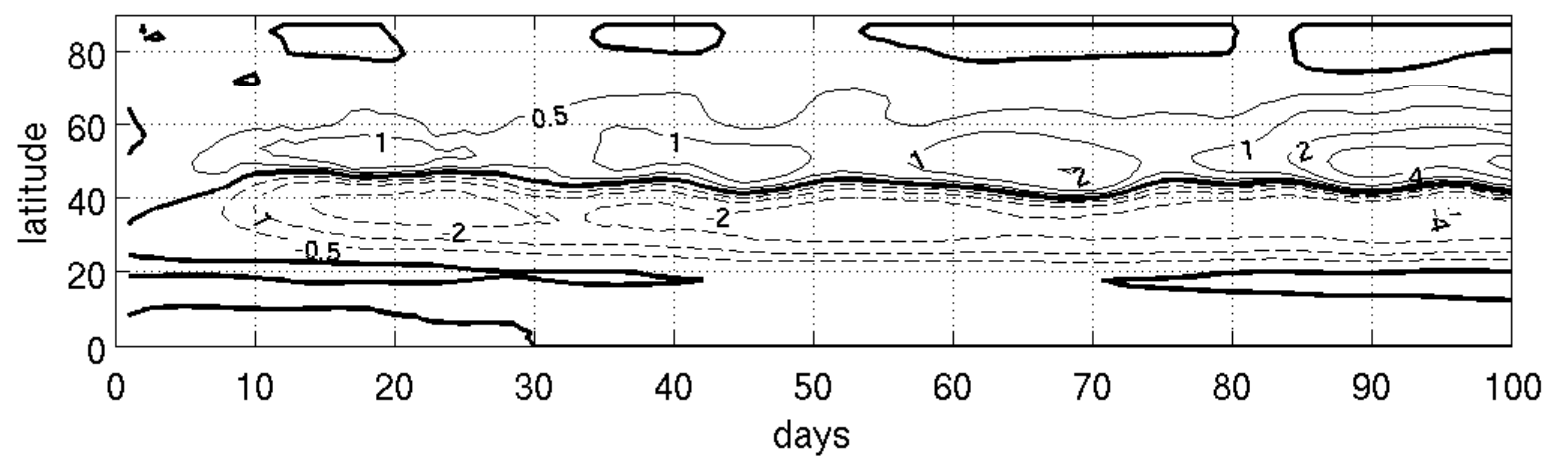

d) EN-LN 6-13km mean sum of $Q G u^{\prime} v^{\prime}$ and $v^{\prime} T^{\prime}$ acceleration

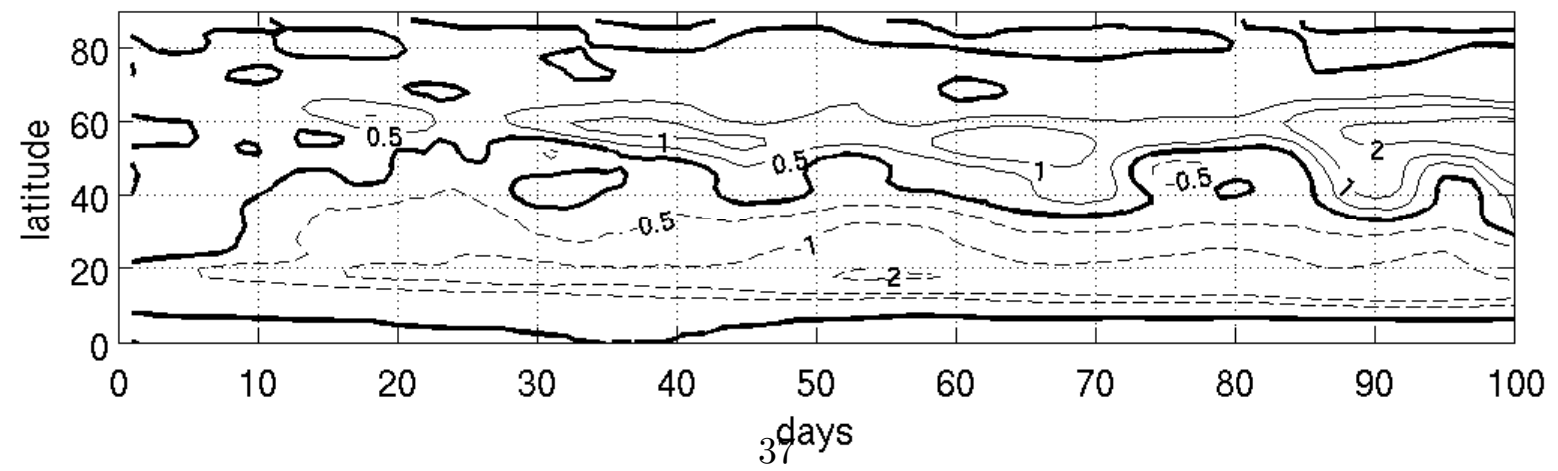

Figure 7: As in figure 5, only using the eddy momentum and heat fluxes calculated from the linear QG model. Note that plot (a) of $U_{P A C}$ is similar between the two figures, since it is used as input for the model. Note also that significance levels are irrelevant, and the magnitudes of wave flux quantities from the linear QG model are arbitrary. 

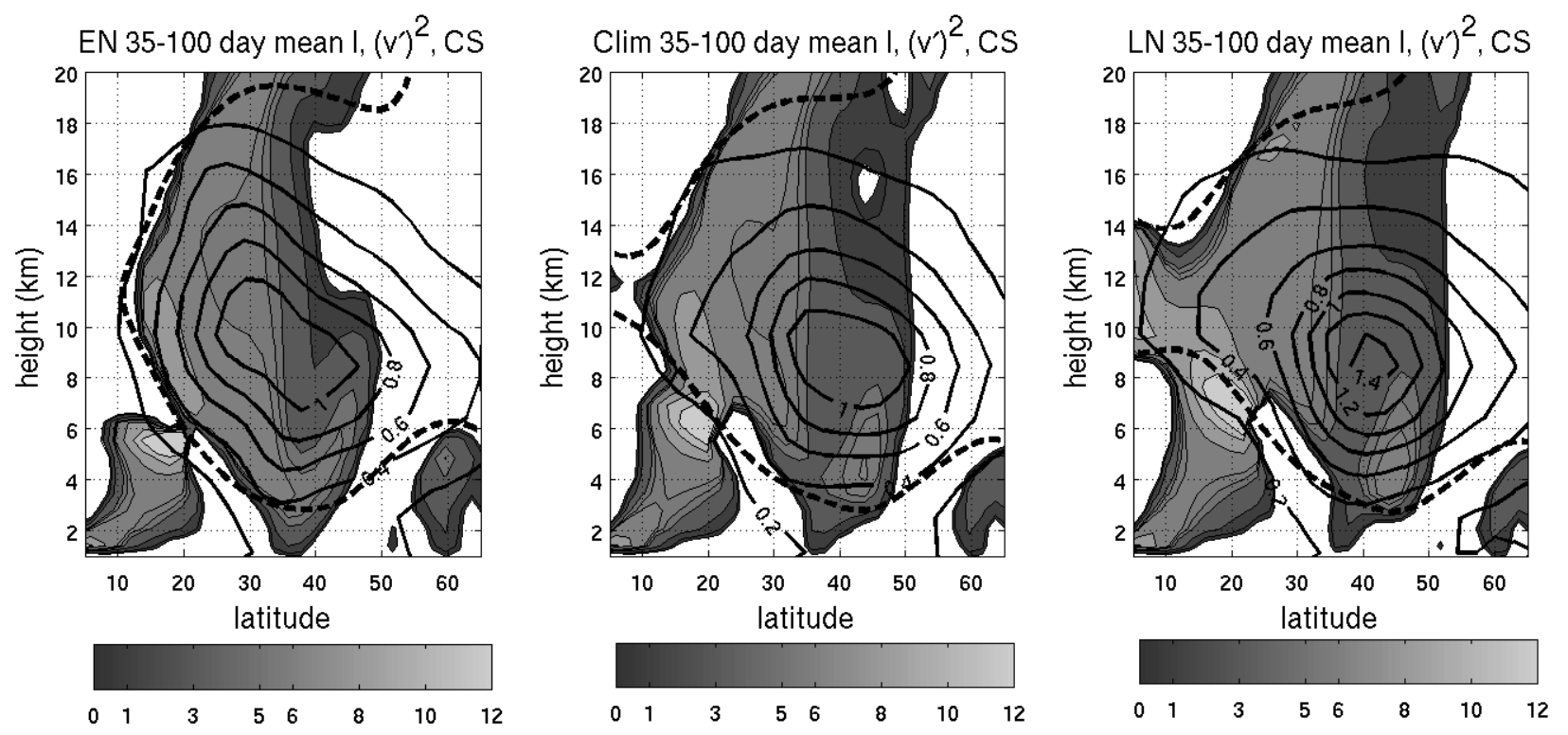

Figure 8: Latitude-height plots of the Pacific region 35-100 day means of the meridional wavenumber $\left(\mathrm{rad}^{-1}\right)$ calculated from the linear QG model (shading, only propagation regions are shown), and the GCM Ensemble mean $\left\langle\overline{v^{\prime 2}}\right\rangle\left(\mathrm{m}^{2} / \mathrm{sec}^{2}\right.$, contours) and the critical surface (dashed thick line), for a) EN, b) Climatology, and c) LN. 